\title{
Reseña de Sentencias del Tribunal Constitucional sobre la Administración Local y Autonómica que aparecen publicadas en el BOE, durante el primer semestre de 1995
}

\author{
Francisco Javier Fernández González \\ Profesor Titular de Derecho Administrativo \\ Universidad de Oviedo
}

Sumario: 1. FUENTES. NORMAS INTRAPARLAMENTARIAS. 2. EMPLEO PÚBLICO. 3. CARGOS PÚBLICOS. 4. RÉGIMEN ELECTORAL. 5. ACTIVIDAD SANCIONADORA. 6. VIVIENDA. 7. DERECHO PÚBLICO DE LA ECONOMÍA: A) Seguros. B) Juegos y Apuestas. 8. EDUCACIÓN. 9. SANIDAD.

\section{FUENTES. NORMAS INTRAPARLAMENTARIAS}

1. Recurso de amparo núm. 1.623/94, promovido por un Diputado del Parlamento de Cataluña contra el Acuerdo de la Mesa del Parlamento de Cataluña de 8 de febrero de 1994 por el que se aprueba la «Norma supletoria del articulo 19 del Reglamento, sobre la participación del Grupo Mixto en las actividades de la Cámara». El demandante de amparo entiende vulnerado su derecho fundamental a acceder en condiciones de igualdad a las funciones y cargos públicos. El TC otorga el amparo.

«Tras la STC 119/1990, debe concluirse que las resoluciones intraparlamentarias de desarrollo reglamentario son susceptibles de impugnación a través del recurso de amparo constitucional, por lo que, cabe añadir, que el recurso de inconstitucionalidad queda reservado únicamente para el eventual control de constitucionalidad de los Reglamentos de las Asambleas, según el tenor del artículo $27.2 \mathrm{~d}$ ) y f ) de la LOTC. De este modo, mejor se salvaguarda la autonomía constitucionalmente garantizada de las Cámaras parlamentarias, pues, sólo cuando las normas internas dictadas para suplir o interpretar el Reglamento sean contrarias a sus contenidos, vulnerando los derechos fundamentales de los 
parlamentarios recurrentes, será posible la fiscalización constitucional de las mismas por parte de este Tribunal» (vid. f.j. 2).

«Las normas supletorias del Reglamento de la Cámara no se incorporan al mismo. Los Reglamentos parlamentarios cumplen una función de ordenación interna de la vida de las Cámaras íntimamente vinculada a la naturaleza representativa y al pluralismo político (artículos 66.1 y 1.1 C.E.) del que tales organos son expresión y reflejo. Esto explica que la propia Constitución, para el caso de las Cortes Generales (artículo 72.1), y la Ley 3/1983, de 25 de marzo, en lo que más directamente atañe al Parlamento de Cataluña (artículo 8.3), requieran para su aprobación y modificación el voto favorable de la mayoría absoluta de sus miembros. Exigencia que se erige, así, en garantía de los derechos de las minorías.

En consecuencia, las demás normas intraparlamentarias dictadas por los órganos competentes de la Cámara encuentran su límite en el Reglamento mismo al que interpretan o suplen, de suerte que, a su través, no es jurídicamente lícito proceder a una modificación del Reglamento, sustrayendo esa decisión al Pleno de la Cámara y obviando, además, el requisito de la mayoría absoluta que, para su reforma, establecen la Constitución, los Estatutos de Autonomía y normas de desarrollo directo de los mismos. Por ello mismo, cuando el artículo 23.2 de la Constitución reconoce a los representantes políticos el derecho de acceder y permanecer en su cargo en condiciones de igualdad "con arreglo a lo dispuesto en las leyes", ese derecho a un ejercicio igual de sus funciones dentro de la legalidad parlamentaria no puede desvincularse de la reserva constitucional o estatutaria de Reglamento, pues como se declaró en la STC 119/1990 «aun aceptando la hipótesis de un uso normativo preexistente, es evidente que tal uso no genera normas con rango de ley, que es el exigido por el artículo 23.2 de la Constitución para establecer condiciones o requisitos en el acceso a los cargos públicos y más generalmente, por el artículo 53.1 de la misma, para regular el ejercicio de los derechos fundamentales» (fundamento jurídico $4 .^{\circ}$ ). De este modo, aquellas disposiciones parlamentarias que, dictadas ultra vires, lejos de suplir o interpretar el Reglamento, manifiestamente innoven o contradigan sus contenidos, implican no sólo una quiebra de la apuntada reserva reglamentaria, sino también una vulneración del citado derecho fundamental» (vid. f.j. 3).

«En el presente recurso, como pone de manifiesto el Letrado del Parlamento de Cataluña en su escrito de alegaciones, la Norma supletoria del artículo 19 del Reglamento de la Cámara fue dictada en atención a 
RESEÑA DE SENTENCIAS DEL TRIBUNAL CONSTITUCIONAL SOBRE LA ADMINISTRACIÓN LOCAL...

una circunstancia nueva y expresamente no prevista en el Reglamento parlamentario que, además, se producía por primera vez en la práctica parlamentaria de aquella Asamblea, a saber: la formación, en el curso de la legislatura, de Grupo Parlamentario Mixto integrado por un solo parlamentario. La existencia de este Grupo Mixto unipersonal aconsejaba, a juicio de la Mesa de la Cámara, una limitación de sus facultades de actuación intraparlamentaria respetuosa, de una parte, con los derechos individuales del parlamentario que lo integraba, pero que, a su vez, no lo equiparase en todo a los demás grupos parlamentarios, dado que éstos, a diferencia de aquél, asumen la representación institucionalizada de una pluralidad de parlamentarios, cuya voluntad conjunta transmiten. Por ello, con apoyo en la literalidad del citado artículo 19 del Reglamento en el que, a diferencia de lo dispuesto en la gran mayoría de las Asambleas legislativas españolas, no se exige que la participación del Grupo Mixto en las actividades del Parlamento sea idéntica a la de los demás grupos sino "análoga», y oída la Junta de Portavoces la Mesa de la Cámara acordó dictar un Acuerdo interpretativo que permitiese singularizar el mandato genérico del artículo 19 del Reglamento a esa nueva circunstancia que suponía la creación de un Grupo Mixto unipersonal. Acuerdo interpretativo al que, además, se le quiso dotar de vocación de futuro revistiéndolo de carácter normativo mediante su publicación como Norma supletoria del Reglamento de la Cámara.

Así considerada, la citada Norma supletoria no supondría, en principio, una modificación indirecta del Reglamento de la Cámara, ni una ampliación injustificada de sus contenidos normativos, sino, más bien, una adaptación integradora de sus contenidos, motivada por la singularidad de un supuesto de hecho desconocido hasta entonces en la vida de la Cámara. En este sentido, no es ocioso-recordar que este Tribunal declaró que no lesionaban el artículo 23 de la Constitución aquellas resoluciones de las Cámaras parlamentarias por las que se reducía la subvención fija del Grupo Mixto o se modulaba su participación en las Comisiones de la Cámara cuando, precisamente, éste estaba integrado por un solo parlamentario (STC 214/1990). Por lo tanto, una atemperación de las facultades de actuación parlamentaria del Grupo Mixto que obedezca al hecho de encontrarse éste formado por un único parlamentario no puede reputarse contraria al artículo 23.2 de la Constitución, siempre que el parlamentario en cuestión no sea privado de sus derechos individuales y de participación en la Cámara, como representante que es de los ciudadanos.

Ahora bien, el Acuerdo interpretativo contra el que se recurre no se limitó a especificar los contenidos del Reglamento, adaptándolo a las 
peculiaridades del mencionado supuesto de hecho, para ofrecer una solución con vocación normativa, en el marco de las facultades que, a tal fin, el propio Reglamento de la Cámara otorga a la Mesa, y con apoyo en el régimen "análogo» que el artículo 19 del Reglamento dispone para el Grupo Mixto. Antes al contrario, en él se estableció una diferencia de trato normativo en atención a las circunstancias de la persona, sin existir previsión reglamentaria alguna sobre esa particular cuestión.

En efecto, como con mayor detalle se reproduce en los antecedentes, al proceder el parlamentario recurrente de otro grupo parlamentario en el que causó baja (el constituido por la fuerza política por cuyas listas se presentó a las elecciones), la Mesa de la Cámara, atendiendo a esta circunstancia, decidió, queriendo dar respuesta «a la opinión ciudadana que, en general, rechaza el transfuguismo político" (según se recoge en el acta de la sesión), desdoblar el régimen de funcionamiento del Grupo Mixto en razón de la procedencia de los parlamentarios que lo integrasen, creando ex novo, mediante su Acuerdo, una distinta y normativamente innovadora configuración reglamentaria del mismo, haciendo un uso impropio de sus facultades para suplir e interpretar el Reglamento y otorgando un trato normativo diferenciado al parlamentario recurrente -al que se incluye, acto seguido, en el régimen más restrictivo de la norma-, sin someter previamente al Pleno de la Cámara aquella decisión que manifiestamente crea Reglamento, y sin que la misma fuese aprobada por la mayoría absoluta de sus miembros.

Precisamente por ello, resulta innecesario pronunciarse aquí sobre la constitucionalidad del criterio utilizado por la Mesa para justificar el establecimiento de regímenes jurídicos diferenciados en el seno del Grupo Mixto y que centra buena parte del debate procesal, pues, a los efectos de la resolución del presente recurso, basta con constatar que, a través de una norma de la Mesa, ésta extralimitando sus facultades normativas de interpretación y suplencia del Reglamento, modificó el régimen jurídico de funcionamiento interno del Grupo Mixto, por razón, no del hecho de encontrarse constituido por un único miembro, sino en atención a la procedencia política del mismo, sin que este criterio de diferenciación, de indudable trascendencia por las consecuencias jurídicas que se vinculan a la decisión que adopten los parlamentarios respecto al eventual abandono de su grupo parlamentario de origen, fuese aprobado por la mayoría absoluta de la Cámara. Que se introdujese por una Norma supletoria porque no existía consenso en el interior de la Asamblea para emprender la reforma del Reglamento - como alega el Letrado del Parlamento de Cataluña-, lejos de justificar la decisión de la Mesa, abunda en lo anteriormente expuesto, y evidencia que a su través 
RESEÑA DE SENTENCIAS DEL TRIBUNAL CONSTITUCIONAL SOBRE LA ADMINISTRACIONN LOCAL...

se pretendió hacer lo que sólo se podía conseguir mediante una reforma del Reglamento» (f.j. 4).

«Pero, además, en el supuesto que ahora nos ocupa, no sólo se vulneró esa dimensión formal del derecho reconocido a los parlamentarios por el artículo 23.2 de la Constitución. También se lesionó el derecho a la igualdad que, materialmente, constituye su contenido. En efecto, al introducirse el citado criterio de diferenciación, después de iniciada la legislatura y mediante una utilización con fines normativos de las circunstancias del caso concreto, el Acuerdo impugnado se dictó ad casum, con el confeso fin de discriminar jurídicamente al parlamentario recurrente, a través de la alteración a posteriori del estatuto del Grupo Mixto al que obligatoriamente tenía que incorporarse, produciéndose una suerte de retroactividad impropia pues, el Acuerdo normativo recurrido limitó sus facultades de actuación parlamentaria en función, exclusivamente, de su previo comportamiento político parlamentario, sancionándolo ex post factum, con apoyo en un criterio de diferenciación introducido específicamente en atención a la conducta del parlamentario y respecto del cual no existía previsión normativa alguna que pudiese servir de soporte a la decisión de la Mesa de la Cámara» (f.j. 5).

"En virtud de cuanto antecede, la demanda de amparo debe ser estimada. En efecto el artículo 23.2 C.E. garantiza el acceso a los cargos públicos en condiciones de igualdad, con arreglo a lo dispuesto en las leyes. Pero cuando se trata de cargos públicos representativos de naturaleza política y elegidos directamente por los ciudadanos, ese derecho fundamental, por conexión con el 23.1 de la propia Constitución, alcanza también al derecho a permanecer en los mismos y a no verse ilegítimamente discriminados en el ejercicio de sus funciones, según la configuración legal de las mismas (por todas, SSTC 7/1992 y 30/1993). Cuando de parlamentarios se trata, esa legalidad no es otra que la contenida en el Reglamento de la Cámara y en aquellas otras normas derivadas que lo suplen o lo interpretan. Sin embargo, el establecimiento de un trato diferenciado a través de una norma supletoria que no se limita a cubrir eventuales lagunas normativas del Reglamento o a concretar sus contenidos en su proyección a un determinado supuesto de hecho, sino que crea ex novo Reglamento, al regular de manera diferenciada las facultades de los miembros del Grupo Mixto con apoyo en un criterio (el de la incorporación directa a ese Grupo o el de la incorporación por baja en otro) introducido por primera vez en la norma misma, y en perjuicio directo del único miembro perteneciente a aquél, no sólo supone una modificación indebida del Reglamento de la Cámara y una quiebra de la garantía formal de la exigencia de mayoría absoluta al servicio del 
valor pluralismo político (artículo 1.1 C.E.), sino también una lesión directa del derecho fundamental del parlamentario demandante a ejercer sus funciones representativas en condiciones de igualdad con «arreglo a lo dispuesto en las leyes", que reconoce el artículo 23.2 C.E.» (f.j. 6).

Fallo: Estimar la demanda de amparo y, en su virtud:

1. Reconocer el derecho del demandante, ex artículo 23.2 C.E., a no ser discriminado y a ejercer sus funciones representativas en condiciones de igualdad con arreglo a lo previsto en el Reglamento de la Cámara.

2. Declarar la nulidad de la Norma supletoria del Reglamento del Parlamento de Cataluña de 8 de febrero de 1994.

(Sentencia n. ${ }^{\circ} 44 / 1995$, de 13 de febrero. Sala Primera. BOE 18-31995. F. García-Mon y González-Regueral).

\section{EMPLEO PÚBLICO}

1. Recurso de amparo núm. 3.002/93, interpuesto contra la Sentencia de la Sala de lo Contencioso-Administrativo del Tribunal Superior de Justicia de Castilla-La Mancha, de 16 de julio de 1993, que estimó el recurso contencioso-administrativo deducido contra la Orden de la Consejería de Administraciones Públicas de la Junta de Comunidades de Castilla-La Mancha, de 11 de marzo de 1992, que resolvió el concurso de traslado para la provisión de puestos de trabajo vacantes en la Administración de la Junta de Comunidades de Castilla-La Mancha. El recurrente en amparo imputa a la sentencia incurrir en contradicción intrínseca, pues realizado el recuento total de la puntuación rectificada otorgada a cada uno de los aspirantes, atribuye el puesto de trabajo a quien ha obtenido menor puntuación. El TC otorga el amparo al entender vulnerado el derecho a la tutela judicial efectiva.

«El presente recurso de amparo se dirige contra la Sentencia de la Sala de lo Contencioso de Castilla-La Mancha, con sede en Albacete, de 16 de julio de 1993, a la que se imputa la vulneración del derecho fundamental a la tutela judicial efectiva reconocido en el artículo 24.1 C.E. Según afirma el demandante, la lesión se habría producido porque en la Sentencia se asigna el puesto de trabajo disputado al entonces recurrente en el proceso contencioso a pesar de que, aplicando los criterios correctores de las puntuaciones contenidas en sus propios fundamentos 
RESEÑA DE SENTENCIAS DEL TRIBUNAL CONSTITUCIONAL SOBRE LA ADMINISTRACIÓN LOCAL...

jurídicos, había obtenido una puntuación inferior a la del demandante en amparo. De este modo, la Sentencia incurriría en una contradicción intrínseca, pues realizando el recuento total de la puntuación rectificada a cada uno de los aspirantes, atribuye el puesto de trabajo a quien ha obtenido menos puntos» (vid. f.j. 1).

«Este error, notorio y patente, contenido en el argumento que sirve de soporte al pronunciamiento de la Sentencia de la Sala de lo ContenciosoAdministrativo, supone un claro menoscabo a la efectividad de la tutela judicial, por cuanto se produce una contradicción, ostensible, en el propio razonamiento jurídico de la Sentencia. Así pues, la argumentación que se utiliza como fundamento de la decisión judicial resulta claramente errónea, y es determinante de la incongruencia interna de la Sentencia. La equivocación observada resulta sustancial, pues a ella se supedita el pronunciamiento último de la estimación del recurso, vulnerando el derecho a obtener una resolución motivada y razonada sobre el fondo de la cuestión planteada. La Sala se pronunció estimando el recurso fundándose en un argumento erróneo, que no puede servir como motivo razonable a su decisión, ni satisface las exigencias derivadas del artículo 24.1 C.E.

Ahora bien, constatado este patente error (sin duda irremediable en la vía judicial ordinaria ante la inexistencia de una segunda instancia en los procesos que versan sobre cuestiones funcionariales) no corresponde a este Tribunal, que no constituye Tribunal de apelación alguno, determinar cuál de las diversas interpretaciones de la legalidad ordinaria debe prevalecer en el presente caso, sino tan solo hemos de limitarnos a estimar el presente recurso de amparo y, previa la declaración de nulidad de la Sentencia, hemos de reenviar el asunto al Tribunal de instancia para que con absoluta libertad de criterio dicho órgano solucione el litigio, que aquí queda imprejuzgado, a través de una Sentencia razonada y razonable en Derecho" (f.j. 7).

Fallo: Estimar el presente recurso de amparo y, en consecuencia:

1. Reconocer el derecho a la tutela judicial efectiva del recurrente.

2. Anular la Sentencia de la Sala de lo Contencioso-Administrativo del Tribunal Superior de Justicia de Castilla-La Mancha de 16 de julio de 1993.

3. Retrotraer las actuaciones judiciales al momento anterior a dictar Sentencia, para que una vez depurado el error patente que contiene, el Tribunal dicte nueva Sentencia en el sentido adecuado. 
(Sentencia n. ${ }^{\circ}$ 5/1995, de 10 de enero. Sala Segunda. BOE 11-2-1995. V. Gimeno Sendra).

\section{CARgos PÚblicos}

1. Recurso de amparo num. 147/93, promovido por el Grupo Parlamentario Mixto-Izquierda Unida del Parlamento de Navarra y por dos Parlamentarios Forales integrados en el mismo, contra Resolución de la Junta de Portavoces del Parlamento de Navarra, de 17 de noviembre de 1992, desestimatoria de recurso promovido contra Acuerdo de la Mesa del Parlamento de Navarra, de fecha 9 de noviembre de 1992, por el que se inadmite la moción presentada por el Grupo Parlamentario Mixto-Izquierda Unida instando al Gobierno de Navarra la elaboración de un documento que sirva de base para la realización de un debate sobre el estado de la Comunidad Foral. Los demandantes de amparo alegan la vulneracion del derecho fundamental a acceder en condiciones de igualdad a las funciones y cargos públicos. El TC deniega el amparo por entender que los órganos de gobierno y dirección de la Cámara se han limitado a aplicar las previsiones reglamentarias configuradoras de aquel derecho en términos perfectamente respetuosos con el artículo $23.2 \mathrm{CE}$.

«El objeto del presente recurso de amparo no es otro que determinar si el Acuerdo de la Mesa del Parlamento de Navarra de 9 de noviembre de 1992 confirmado por Resolución de la Junta de Portavoces de 17 de noviembre de 1992, ha conculcado o no el derecho que a los actores reconoce el artículo 23.2 C.E. Derecho este que, según reiterada jurisprudencia, es un derecho de configuración legal, «en la que participan los Reglamentos Parlamentarios, a los que compete regular y ordenar los derechos y atribuciones que los Parlamentarios ostentan; de tal suerte que, una vez conferidos aquéllos por la norma reglamentaria, pasan a formar parte del status propio del cargo parlamentario y sus pretendidas transgresiones pueden ser defendidas ante este Tribunal, al amparo del artículo 23.2, y en cuanto contenido del ius in officium que (se considera) ilegítimamente constreñido" (...)

Toda la cuestión debatida se centra propiamente en determinar si la moción inadmitida por la Mesa es encuadrable en uno u otro de los dos apartados [a) y b)] en los que se estructura el artículo 190 y a los que los preceptos subsiguientes anudan procedimientos y efectos diferentes y, de manera señalada, distintas facultades en punto a la admi- 
RESEÑA DE SENTENCIAS DEL TRIBUNAL CONSTITUCIONAL SOBRE LA ADMINISTRACIÓN LOCAL..

sión o inadmisión de las mociones por parte de la Mesa de la Cámara» (vid. f.j.l).

"Las facultades atribuidas a la Mesa en punto a la admisión o inadmisión de mociones varían sensiblemente en función del tipo de moción presentada. Así, las encuadrables en el artículo 190 a) «deberán ser admitidas a trámite», si bien podrá rechazarse su inclusión en el orden del día del Pleno si son idénticas a mociones ya votadas por el Parlamento en el mismo período de sesiones (artículo 191.3). Por su parte, las mociones a las que se refiere el artículo 190 b) no resultan de admisión a trámite automática, pues el artículo 192.1 del Reglamento atribuye a la Mesa la facultad de decidir sobre su admisión, lo que claramente indica que los poderes de la Mesa se extienden más allá de la simple verificación de la corrección formal de la moción hasta extenderse a juicios de oportunidad, vedados a la Mesa cuando de mociones ex artículo 190 a) se trata. Tanto los demandantes de amparo como el Ministerio Público sostienen que la moción rechazada encontraba su acomodo reglamentario en el artículo 190 a), de manera que, no concurriendo la circunstancia prevista en el artículo 191.3, la Mesa no podía sino, verificada su legalidad formal admitirla a trámite ex artículo 191.2. Por su parte, el Parlamento de Navarra alega que la moción no hacía referencia alguna al artículo 190 a) y que el Grupo proponente se había limitado en ella a ampararse en una supuesta costumbre parlamentaria. Para el Parlamento, es evidente que, atendido el contenido mismo de la moción, fácilmente se deduce que sólo cabe clasificarla como moción ex artículo 190 b), precepto este que, además, fue el utilizado en su día para provocar el único debate sobre el estado de la Comunidad Foral que ha tenido lugar en el Parlamento.

Así planteados los términos del debate y a la vista de las posiciones mantenidas por los actores y el Ministerio Fiscal, de un lado, y el Parlamento de Navarra, por otro, no queda sino dilucidar qué tipo de moción era la presentada y rechazada, pues de tal calificación habrá de depender la definición de las facultades propias de la Mesa y, subsiguientemente, el enjuiciamiento de la decisión por ella adoptada y confirmada por la Junta de Portavoces» (vid. f.j. 2).

"No cabe ninguna duda de que, pese a lo sostenido en su escrito de alegaciones por el Ministerio Fiscal, la moción no podía encuadrarse en el artículo 190 a) del Reglamento de la Cámara. Y ello porque, frente a lo alegado, es evidente que no se trataba de una moción dirigida al Gobierno, sino al propio Parlamento. Basta atender a la literalidad del artículo 190 a) para apreciar que difícilmente podía encajarse la moción 
en ese apartado, pues en él se hace referencia a las mociones que pretendan "que la Diputación Foral formule una declaración sobre un tema o remita al Parlamento un Proyecto de Ley Foral regulando una materia de la competencia de éste"». Es claro, en primer lugar, que con la moción no se pretendía la remisión de un Proyecto de Ley Foral; también, en segundo término, que no se pretendía con ella la formulación de una declaración por parte del Gobierno sobre un tema. Antes al contrario, lo que se perseguía era, más bien, que se pusieran de manifiesto «las diferentes opiniones y posturas de los Grupos Parlamentarios sobre los temas más candentes de la actualidad, posibilitando la adopción de las Resoluciones pertinentes" por parte del propio Parlamento.

Ciertamente, se interesaba la elaboración, por el Gobierno, de un documento que habría de ser remitido a la Cámara; pero tal documento no habría de servir a otros fines que a los meramente instrumentales de facilitar un debate parlamentario que sirviera para dar a conocer las posiciones de los Grupos y del que podrían resultar Resoluciones parlamentarias. En otras palabras, y con toda claridad, se pretendía una deliberación y pronunciamiento parlamentarios sobre determinado asunto, más que la declaración gubernamental sobre un tema; pretensión que, con toda evidencia encuentra perfecto acomodo en la literalidad del artículo 190 b): "Que el Parlamento delibere y se pronuncie sobre un determinado asunto cualquiera que sea el objeto sobre el que éste verse, o que la Cámara delibere y se pronuncie sobre un texto de carácter no legislativo»» (vid. f.j. 3).

«No tratándose de una moción ex artículo 190 a) del Reglamento Parlamentario - según un criterio que no puede reputarse irrazonable o arbitrario sino fundado en las necesidades de ordenación del trabajo de la Cámara y que este Tribunal, consiguientemente, ha de respetar-, es obvio que, a los fines de su admisión a trámite, no podía operar el automatismo propio del artículo 191.2, sino que resultaba de aplicación el artículo 192.1, en cuya virtud "las mociones a que se refiere el apartado b) del artículo 190, deberán presentarse por escrito dirigido a la Mesa de la Cámara, que decidirá sobre su admisión a trámite, ordenará, en su caso, su publicación y acordará su tramitación ante el Pleno o la Comisión competente, en función de la voluntad manifestada por el Grupo o Parlamentario Foral proponente y de la importancia del tema objeto de la moción".

Llegados a este punto, y descartada la admisión automática de la moción, es preciso determinar si las razones argüidas para justificar su rechazo se compadecen o no con las previsiones reglamentarias y resul- 
RESEÑA DE SENTENCIAS DEL TRIBUNAL CONSTITUCIONAL SOBRE LA ADMINISTRACIÓN LOCAL...

tan, en consecuencia, respetuosas o contrarias para con el derecho fundamental pretendidamente conculcado. En este sentido, y como bien señala el Ministerio Público, el hecho de que el Acuerdo de la Mesa fuera inmotivado no supone, per se, vulneración alguna del artículo 23.21 C.E., pues la Junta de Portavoces ha incorporado a aquel Acuerdo una motivación suficiente.

Motivación que, además, y como habrá de verse, es también ajustada y conforme al derecho supuestamente vulnerado. En efecto la inadmisión se ha fundamentado en la circunstancia de que no cabía atender la pretensión principal de los proponentes - esto es, que se celebrara un debate sobre el estado de la Comunidad antes del 31 de diciembre de 1992 - habida cuenta de que la Cámara - por imperativo legal y reglamentario - habría de consagrarse, en el período que mediaba entre la presentación de la moción (noviembre de 1992) y ese término a quo, a la elaboración de la Ley Foral de Presupuestos. A ello no cabe oponer, como propone el Ministerio Público, que, en la medida en que se interesaba la remisión, por el Gobierno, de un documento, la moción debió ser admitida ex artículo 190 a) y, en su caso, acordar la celebración del debate plenario para una fecha posterior a la propuesta. De un lado, porque el documento interesado no tenía cabida, según se ha visto, en el precitado artículo 190 a); de otro, porque lo principalmente interesado era, precisamente, la celebración del debate, lo que supone, además de la clara incardinación de la moción en el artículo 190 b), que las facultades de examen de la Mesa eran más amplias que las estrictamente conferidas en el artículo 191.2 y que entre las circunstancias apreciables por la Mesa en orden a la decisión sobre la admisión o inadmisión de la propuesta debía necesariamente figurar dato tan relevante como el temporal -fijado por el propio Grupo proponente-, del que resultaba inevitable deducir, habida cuenta de la necesaria consagración de la Cámara a la elaboración de la Ley Foral de Presupuestos, la imposibilidad de dar trámite a la moción presentada. De no haber sido por el condicionamiento temporal de la celebración del debate, nada hubiera impedido la admisión de la propuesta, pues entonces hubiera sido posible acordar la celebración del debate en el momento pertinente, tal y como, según alega el Parlamento, sucedió con el anterior y único debate sobre el estado de la Comunidad habido en el Parlamento de Navarra. Al haber fijado ese condicionante el propio Grupo Parlamentario proponente, la Mesa no podía sino - calificada, acertadamente, la moción como una de las referidas en el artículo 190 b) del Reglamento de la Cámara- inadmitida por inviable en razón de las necesidades -insoslayables-de programación del Pleno. 
Así las cosas, y por cuanto acaba de referirse, la demanda de amparo no puede prosperar, pues con las Resoluciones parlamentarias impugnadas no se ha vulnerado en absoluto el derecho reconocido en el artículo 23.2 C.E. Los órganos de gobierno y dirección de la Cámara se han limitado a aplicar las previsiones reglamentarias configuradoras de aquel derecho en términos perfectamente respetuosos con el precepto constitucional supuestamente infringido" (f.j. 4).

Fallo. Desestimar el presente recurso de amparo.

(Sentencia n. ${ }^{\circ} 41 / 1995$, de 13 de febrero. Sala Segunda. BOE 18-31995. J.D. González Campos).

\section{RÉGIMEN ELECTORAL}

1. Recurso de amparo electoral núm. 1.653/95, promovido por el representante general electoral del partido político "Los Verdes Alternativos", contra la Sentencia de 5 de mayo de 1995, de la Sección Electoral de la Sala de lo Contencioso-Administrativo del Tribunal Superior de Justicia de Madrid, desestimatoria del recurso contencioso-electoral interpuesto por "Los Verdes Alternativos" contra proclamación de la candidatura presentada por la coalición electoral denominada "Los Verdes-Grupo Verde" para la Asamblea de la Comunidad de Madrid. El partido recurrente en amparo aduce que la identidad de denominación, siglas y símbolo utilizados por la coalición "Los Verdes-Grupo Verde» induce a confusión con las suyas propias, vulnerándose asi el derecho fundamental a acceder en condiciones de igualdad a las funciones y cargos públicos. El TC deniega el amparo.

"Concluido, pues, que ningún partido político, coalición electoral o grupo de electores puede hacerse en exclusiva con las mencionadas representaciones auténticas de líneas de pensamiento, ello conlleva que entre las denominaciones y signos enfrentados, cuya comparación ha de hacerse en su conjunto (denominaciones y gráficos a la par), sin destacar aisladamente alguno de sus elementos para poner de manifiesto una similitud que en su globalidad no existe, no se da el denunciado riesgo de confusión lesivo del derecho de acceso en condiciones de igualdad a los cargos públicos del artículo 23.2 de la Constitución.

En el presente caso, ambas candidaturas electorales utilizan la expresión «Los Verdes» (como ha quedado dicho no apropiable por nadie 
RESEÑA DE SENTENCIAS DEL TRIBUNAL CONSTITUCIONAL SOBRE LA ADMINISTRACIÓN LOCAL..

con exclusión de los demás), pero en la denominación del partido político se agrega la palabra "Alternativos» en tanto que en el caso de la coalición electoral demandante el complemento es «Grupo Verde». Si a ello se añade que los dos gráficos son también diversos, diversidad que aún será más clara en las papeletas electorales debido a que su reducción de tamaño, al pasar a ellas, hace destacar aún más en el caso del girasol su círculo interior negro y en el del sol sonriente el círculo interior blanco, hemos de concluir que, en esa apreciación de la totalidad de ambas representaciones mixtas (denominaciones y gráficos) no existe el riesgo dé confusión que la Ley trata de evitar, a diferencia de lo que podía ocurrir hace unos años cuando al término "verde" no se le había atribuido en nuestro país el significado genérico que ha venido adquiriendo y que llevó en aquel momento a dictar la alegada STC 107/1991" (f.j. 3).

«Por último, como señala el Ministerio Fiscal, el partido ahora recurrente debió proceder en su día contra la denominación de los partidos que han constituido la coalición electoral «Los Verdes-Grupo Verde». Al no haberlo hecho, no puede ahora pretender la exclusión de las candidaturas presentadas por dicha coalición, pues el proceso electoral no es el cauce idóneo para esos fines. En otras palabras la coincidencia en la denominación existía con anterioridad a la constitución de la coalición y, por tanto, al no haber actuado en su momento contra esa coincidencia, no puede ahora combatirla por el solo hecho de que la coalición haya hecho suyas las denominaciones de los partidos coligados. De suerte que la proclamación de las candidaturas presentadas por la coalición "Los Verdes-Grupo Verde» no ha podido inducir a más confusión que la que ya pudiera existir anteriormente con la coexistencia de la denominación del partido recurrente y las de los partidos que han dado vida a la coalición, sin que tal circunstancia haya sido oportunamente combatida, en la vía ordinaria, por el actor. No es de apreciar, en definitiva, lesión alguna de derechos fundamentales que pueda ser amparada por este Tribunal» (f.j. 4).

Fallo: Desestimar el presente recurso de amparo electoral.

(Sentencia n. ${ }^{\circ}$ 70/1995, de 11 de mayo. Sala Segunda. BOE 13-61995. F. García-Mon y González-Regueral).

2. Recurso de amparo electoral núm. 1.657/95, interpuesto por el representante general de la coalición electoral "Los Verdes-Grupo Verde", contra la Sentencia que la Sección Electoral de la Sala de lo Conten- 
cioso-Administrativo del Tribunal Superior de Justicia de Madrid de 5 de mayo de 1995, que desestimó el recurso contencioso electoral sobre proclamación de candidatura del partido político "Los Verdes Alternativos». Los demandantes de amparo entienden vulnerado su derecho fundamental a obtener la tutela efectiva de Jueces y Tribunales pues a su juicio la Sentencia impugnada no ha dado respuesta a todas y cada una de las cuestiones suscitadas en la demanda correspondiente; asimismo consideran violado su derecho a acceder en condiciones de igualdad a las funciones y cargos públicos debido a que los signos identificadores y logotipos utilizados por el partido "Los Verdes Alternativos" pueden inducir a confusión a los electores. El TC deniega el amparo.

"Conviene abordar inmediatamente después el reproche que se imputa a la Sentencia de la Sala de lo Contencioso-Administrativo por su carácter formal en principio, aun cuando contenga también resonancias sustantivas. Se trata de la congruencia como elemento interno de la decisión judicial (artículo 359 L.E.C. ) y, en este caso, de una de las modalidades de su carencia total o parcial la incongruencia ex silentio, por otro nombre omisiva. En opinión de este Tribunal Constitucional sólo se menoscaba la plenitud de la tutela judicial cuando el órgano judicial deja sin contestar las pretensiones de las partes, sometidas a su conocimiento, siempre que el silencio judicial no puede razonablemente interpretarse como una desestimación tácita (STC 368/1993). Ahora bien, para que tal tacha sea atendible en esta sede, debe comprobarse si concurren dos datos esenciales: Uno, el efectivo planteamiento del problema y otro la ausencia de respuesta razonada por parte del juzgador (SSTC 5/1990 y 87/1994).

Es inconcuso que se da el primero de tales elementos, cuya existencia nadie discute. Efectivamente, en la demanda del recurso contencioso-electoral, donde se pedía la nulidad de la proclamación de la candidatura de "Los Verdes Alternativos", se alegaron tres causas distintas pero convergentes para justificar tal pretensión: Una, que este partido político quedó disuelto el 24 de enero de 1993; otra, que quienes actúan como sus representantes legales también lo son de "Los Verdes" o "Los Verdes de Madrid" y, en tercer lugar, que quiere utilizar en las papeletas electorales un logotipo muy parecido al de "Los Verdes-Grupo Verde», con riesgo de confusión en los electores. En ésta centra su atención exclusivamente la Sentencia impugnada, que deja de lado y olvida por completo las otras dos. Se produce así la incongruencia defectiva antes descrita, que sería suficiente, por sí sola, para provocar su anulación. 
RESEÑA DE SENTENCIAS DEL TRIBUNAL CONSTITUCIONAL SOBRE LA ADMINISTRACIÓN LOCAL...

Tal silencio puede calificarse como denegación de justicia y en la misma medida, menoscaba la efectividad de la tutela judicial (entre otras, SSTC 29/1987, 8/1989, 5/1990 y 53/1991), desde el momento en que unas cuestiones planteadas y pertinentes para la decisión de la contienda no han recibido respuesta alguna del juzgador, sin que por otra parte pueda colegirse que hayan sido tácitamente rechazadas por él. Se trata, lisa y llanamente de un olvido y de una omisión no deliberada, quizá originada por la celeridad del procedimiento y la premura de los plazos, que han sido observados, sin salirse ni un instante de ellos, por la Sala. Esta conclusión no puede ni debe, sin embargo, conducirnos a la que sería la solución normal y ortodoxa en un amparo ordinario, la nulidad de la Sentencia con retroacción de las actuaciones para que el Tribunal ordinario dicte otra nueva, dando respuesta a todas y cada una de las cuestiones suscitadas en el contencioso-electoral, por no permitirlo la perentoriedad de los plazos del proceso electoral antes señalada, ya que, además, este Tribunal tiene el suficiente conocimiento de los hechos para enjuiciar, aquí y ahora, las tres cuestiones planteadas y, en definitiva, su objeto primario: Si la proclamación de la candidatura presentada por el partido «Los Verdes Alternativos» vulnera el derecho de sufragio pasivo de la coalición electoral demandante (STC 81/1987)" (vid. f.j. 2).

«No habiendo dificultad alguna para la selección de la norma, cuya interpretación por otra parte tampoco ofrece aspectos ambiguos o problemáticos, queda únicamente en pie, como tema a debate, la determinación de los hechos para subsumirlos, una vez establecidos, en su marco normativo. Conviene recordar que ambas operaciones son, en principio, privativas de la potestad de juzgar como contenido de la función jurisdiccional que la Constitución confiere a los Jueces y Tribunales componentes del Poder Judicial, con la absoluta independencia predicada también allí (artículo 117 C.E.) sin perjuicio de la misión propia de este Tribunal Constitucional para garantizar los derechos fundamentales especialmente protegidos (artículo 123 C.E.). Hemos dicho y repetido que el recurso de amparo no es una nueva instancia ni tiene asignada función casacional alguna, que por desarrollarse en el plano de la legalidad corresponde al Tribunal Supremo (STC 37/1995).

Aquí encaja con naturalidad la prohibición de que aquél entre a conocer de los hechos que dieron lugar al proceso [artículo $44.1 \mathrm{~b}$ ), in fine], por ser premisa insoslayable su determinación a través de la actividad probatoria, que comprende la admisibilidad, la pertinencia y la práctica de las pruebas y la valoración de su acervo, con dos dimensiones: Primera la calificación de la validez o licitud de cada una de las 
practicadas, una a una y luego la ponderación de la eficacia, capacidad persuasiva o fuerza comunicante del conjunto en conciencia, pero según las reglas de la sana crítica (ATC 87/1995).

En consecuencia, una vez que el Tribunal Superior de Justicia no fue convencido por los medios probatorios propuestos, admitidos y practicados ante la Sala de lo Contencioso-Administrativo, de que hubiera sido disuelto el 24 de enero de 1993 el partido político «Los Verdes Alternativos», como se alegaba en el escrito de interposición del recurso contencioso-electoral, esa alegación ha de tenerse por desprovista de fundamento, sin posibilidad alguna de revisar en esta sede tal apreciación. Queda, pues, constreñido nuestro discurso a las dos tachas que, habiendo sido formuladas en la vía judicial, no recibieron respuesta alguna en la Sentencia que la puso fin. La primera, consistente en una hipotética doble militancia de los representantes de esa fuerza política, está huérfana también de cualquier apoyo probatorio y carece por tanto de eficacia obstativa para la proclamación de la candidatura correspondiente. No hay, pues, desde esta perspectiva, lesión alguna del derecho de sufragio pasivo de la coalición electoral contendiente, como mantiene el Fiscal ante este Tribunal. La carga de la prueba, onus probandi, se impone en nuestro sistema a quien pretende la exclusión de una candidatura en función de una sedicente irregularidad (artículos 49.1 L.O.R.E.G. y 1.214 C.C.).

Un esquema discursivo paralelo nos permite llegar a una conclusión pareja, también negativa, respecto de una supuesta alteración del logotipo para este proceso electoral. Conviene dejar bien sentado que los logotipos, como signo distintivo de ambas formaciones políticas, partido y coalición, tienen un carácter predominantemente gráfico el diseño, con el que se mezcla un ingrediente denominativo constituido por los nombres respectivos. Se reduce, pues, la cuestión a determinar si los que pretenden utilizar las candidaturas rivales pueden ser confundidos por los electores o votantes como consecuencia de su semejanza (artículo 46.4 L.O.R.E.G.), aspectos uno y otra interconectados y componentes de un concepto jurídico indeterminado. Es claro que tal planteamiento supone la impugnación en última instancia de la inscripción del partido político, con la denominación correspondiente, en el Registro ad hoc, tema que, como es obvio queda extramuros del contencioso-electoral y del amparo subsiguiente. En este aspecto, resulta decisivo el alcance que haya de darse a la prohibición analizada en función de su finalidad no otra sino la de evitar que el elector confunda materialmente una candidatura con otra por la circunstancia de que los elementos para individualizarlas sean idénticos o muy semejantes (STC 106/1991) y asegurar así que la volun- 
RESEÑA DE SENTENCIAS DEL TRIBUNAL CONSTITUCIONAL SOBRE LA ADMINISTRACIÓN LOCAL...

tad política expresada por el sufragio se corresponda, con la mayor fidelidad posible, a la identidad real de quien, a lo largo de la campaña electoral, los recabe (STC 69/1986). Ahora bien, ello no autoriza la entrega en exclusividad a un determinado grupo de "representaciones auténticas" de líneas de pensamiento, "que en un Estado social y democrático de Derecho nadie puede pretender» (STC 106/1991), y, por el contrario, permite que una misma corriente ideológica pueda tener diversas expresiones partidarias con simbología a veces parcialmente coincidente, mientras no induzca a la confusión de los electores (STC 85/1986). Esta conclusión se ve abonada porque tales «representaciones auténticas» de líneas de pensamiento ("socialista», «liberal», «verde», etc.) tienen un manifiesto talante genérico que se refleja necesariamente en las denominaciones cuya genericidad conlleva el uso común por pertenecer al dominio público e impide la apropiación en exclusiva por nadie, ya que además su eficacia distintiva, por esa utilización colectiva y continua, se degrada hasta privarlas de toda capacidad diferenciadora.

Una vez dicho esto queda por averiguar tan sólo si entre ambos logotipos se da la semejanza proclive a la confusión, para lo cual resulta decisiva la impresión de conjunto, desde la totalidad de los elementos de cada uno de ellos, sin descomponer su unidad gráfica y fonética, donde la estructura prevalezca sobre sus componentes parciales. Desde esta perspectiva estructural, el análisis comparativo de los símbolos de las dos candidaturas pone de manifiesto que ambas utilizan la expresión "Los Verdes", no monopolizable por nadie, según quedó dicho anteriormente, pero el partido político le agrega el adjetivo "Alternativos» mientras en el caso de la coalición electoral el complemento es «Grupo Verde». Si a ello se añade que los dos dibujos son también diversos, diversidad que aún será más clara en las papeletas electorales porque la reducción de su tamaño al pasar a ellas hace destacar aún más en el caso del girasol su círculo interior negro y en el del sol sonriente el círculo interior blanco, hemos de concluir que, en esa apreciación global de ambos signos distintivos mixtos (denominativos y gráficos), no existe el riesgo de confusión que la ley trata de prevenir, a diferencia de lo que pudo ocurrir hace unos años cuando al término "verde" aún no se le había atribuido en nuestro país el significado genérico que ha ido adquiriendo y, por ello, en aquel momento esta distinta situación dio lugar a la solución que acoge la STC 107/1991, hoy obsoleta por el cambio de circunstancias. No hay, pues, menoscabo alguno por esta causa del derecho al acceso a los cargos públicos en condiciones de igualdad (artículo23.2 C.E.)»(f.j. 3).

Fallo: Desestimar el presente recurso de amparo. 
(Sentencia n. ${ }^{\circ} 71 / 1995$, de 11 de mayo. Sala Segunda. BOE 13-61995. R. de Mendizábal Allende).

3. Recurso de amparo electoral núm. 1.674/95, promovido por el representante general de la coalición electoral "Alternativa de IzquierdasLos Verdes", contra la Sentencia de la Sección Tercera de la Sala de lo Contencioso-Administrativo del Tribunal Superior de Justicia de Madrid de 5 de mayo de 1995, que estimó el recurso contencioso-electoral interpuesto contra el Acuerdo de la Junta Electoral de Zona de Alcalá de Henares de 1 de mayo de 1995, por el que se proclamó la candidatura de la coalición "Alternativa de Izquierdas-Los Verdes" para el Ayuntamiento de Rivas-Vaciamadrid. La Sentencia impugnada anuló tal proclamación al entender que tenía preferencia la coalición "Los Verdes-Grupo Verde" y procedia en consecuencia rechazar cualquier otra en cuya denominación aparezca la expresión "Los Verdes". La coalición recurrente en amparo aduce, de un lado, la vulneración del derecho a la tutela judicial efectiva, y de otro lado, la vulneración de su derecho a acceder en condiciones de igualdad a las funciones y cargos públicos. El TC otorga el amparo por esta última razón.

«No puede aceptarse la solución adoptada por la Sala de lo Contencioso-Administrativo. Esta debía haber procedido a analizar si, en el caso concreto, se producía o no confusión, es decir, si el resto de los elementos, que junto a la expresión "Los Verdes" integraban la denominación de las coaliciones, unido a los símbolos de cada uno de ellos, aportaban o no una diferenciación suficiente. Desde esta perspectiva, no puede negarse que en las denominaciones de las coaliciones aquí enfrentadas, "Alternativa de Izquierdas-Los Verdes» y «Los Verdes-Grupo Verde", existen elementos que resultan relevantes para entender que están suficientemente diferenciadas, máxime cuando en la actualidad y a diferencia de lo que podía ocurrir hace unos años él término "verde» ha adquirido en nuestro país un carácter genérico como expresión de una determinada ideología o línea de pensamiento.

Procede, por todo lo expuesto, otorgar el amparo solicitado, anular la Sentencia del Tribunal Superior de Justicia de Madrid de 5 de mayo de 1995, y, en consecuencia reconocer la validez de la proclamación realizada por la Junta Electoral de Zona de Alcalá de Henares en relación con la candidatura para el municipio de Rivas-Vaciamadrid de la coalición "Alternativa de Izquierdas-Los Verdes», sin realizar pronunciamiento alguno respecto del símbolo utilizado por la coalición pues, aun- 
RESEÑA DE SENTENCIAS DEL TRIBUNAL CONSTITUCIONAL SOBRE LA ADMINISTRACION LOCAL...

que por «Los Verdes-Grupo Verde» se alegó en el recurso contenciosoelectoral la identidad con el utilizado por ella y que fue reconocido por la Junta Electoral Central, ni en ese momento ni en las alegaciones realizadas ante este Tribunal se ha aportado prueba alguna suficiente para desvirtuar la decisión de la Junta Electoral de Zona de proclamar la candidatura con el símbolo propuesto" (f.j. 6).

Fallo: Otorgar el amparo solicitado y, en su virtud:

1. Anular la Sentencia de la Sección Tercera de la Sala de lo Contencioso-Administrativo del Tribunal Superior de Justicia de Madrid de 5 de mayo de 1995.

2. Reconocer a los integrantes de la candidatura al Ayuntamiento de Rivas-Vaciamadrid de la coalición electoral «Alternativa de Izquierdas-Los Verdes" su derecho a acceder en condiciones de igualdad a los cargos públicos, con los requisitos que señalen las leyes, y, en consecuencia, reconocer la validez de la proclamación de dicha candidatura realizada por la Junta Electoral de Zona de Alcalá de Henares.

(Sentencia n. ${ }^{\circ}$ 72/1995, de 12 de mayo. Sala Segunda. BOE 13-61995. T.S. Vives Antón).

4. Recurso de amparo electoral núm. 1.683/95, promovido por el Partido Socialista Obrero Español (PSOE), contra la Sentencia de la Sala de lo Contencioso-Administrativo del Tribunal Superior de Justicia de Castilla y León, de 6 de mayo de 1995, que estimó parcialmente el recurso contencioso-electoral interpuesto contra el Acuerdo de la Junta Electoral de Zona de Ciudad Rodrigo (Salamanca), de 1 de mayo de 1995, sobre proclamación de candidaturas a elecciones locales en lo que afecta a determinados municipios. La Sentencia impugnada anuló el Acuerdo sobre proclamación de candidaturas en lo relativo a las del Partido Socialista Obrero Español (PSOE) para los municipios de Ituero de Azaba, Martiago y Robleda, por haber sido proclamadas con un candidato menos. Los demandantes de amparo entienden vulnerados los derechos fundamentales a la igualdad y a acceder en condiciones de igualdad a las funciones y cargos públicos. El TC deniega el amparo.

"La cuestión se centra, en consecuencia, en determinar si la anulación de la proclamación de candidaturas con un candidato menos es o no contraria al artículo 23.2 de la C.E. Como se ha expuesto, el recu- 
rrente considera que la respuesta a esta cuestión debe ser afirmativa, ya que los demás candidatos que acreditaron a tiempo que cumplían los requisitos legalmente exigidos no deben verse perjudicados por la falta de un documento de uno de los candidatos, máxime cuando la subsanación de la referida irregularidad fue imposible por causas imputables, no al afectado, sino a la Administración, y cuando por el representante de la candidatura se actuó con toda diligencia para intentar la subsanación. Es preciso insistir, sin embargo, en que la anulación de la proclamación de las candidaturas realizada por el órgano judicial no se basó en la falta de subsanación o la subsanación extemporánea de alguna de las irregularidades sino en que se trataba de candidaturas incompletas y por lo tanto no ajustadas a lo dispuesto en el artículo 46.3 L.O.R.E.G. Es cierto que la proclamación de dichas candidaturas fue hecha por la propia Junta Electoral de Zona, con infracción del mencionado precepto, lo que motivó su posterior anulación en vía jurisdiccional; sin embargo, el recurrente no puede ampararse ahora en una actuación de la Junta que fue consentida por él y de la que pretendió beneficiarse. En la demanda de amparo - y anteriormente en el escrito de contestación al recurso contencioso-electoral- se cuestiona, en efecto, la actuación de la Junta Electoral de Zona, reprochándosele que no permitiera la subsanación tardía de las irregularidades puestas de manifiesto, y que rechazara igualmente la solicitud de subsanación de oficio. Lo procedente hubiera sido entonces impugnar la exclusión de los candidatos; ello hubiera permitido que el órgano jurisdiccional procediera a examinar -al igual que hizo en el caso resuelto por la Sentencia núm. 492- si cabía o no la subsanación y se hubiera evitado, en caso afirmativo, la proclamación de una lista incompleta. Al no hacerlo así, se consintió una proclamación irregular que abría las puertas a ulteriores recursos, lo que efectivamente ocurrió, no quedándole al órgano judicial otra alternativa que la anulación de la proclamación (pues el artículo 47.4 L.O.R.E.G. establece de forma tajante que «no procederá la proclamación de candidaturas que incumplan los requisitos señalados en los artículos anteriores o los que establecen las disposiciones especiales de esta Ley»), sin que en ese momento fuera ya procedente traer a colación la imposibilidad de subsanar las irregularidades advertidas. En consecuencia, no puede apreciarse en la conducta del órgano judicial violación alguna del artículo 23.2 C.E.; más bien sería la concesión de un trato de favor que se esperaba de dicho órgano la que resultaría contraria al mencionado precepto que exige que el acceso a los cargos y funciones públicas se haga con arreglo a lo dispuesto en las leyes y en condiciones de igualdad.

Conviene recordar, por último, que la obligación que tienen los órganos de la Administración electoral de actuar diligentemente (obliga- 
RESEÑA DE SENTENCIAS DEL TRIBUNAL CONSTITUCIONAL SOBRE LA ADMINISTRACIÓN LOCAL...

ción recordada por este Tribunal de forma reiterada: SSTC 73/1986, 59/1987, 85/1987 y 75/1991) no excluye la de los partidos, federaciones, coaliciones y agrupaciones intervinientes en el proceso electoral, que deben velar por la correcta proclamación no sólo de las candidaturas ajenas sino, en primer lugar, de las propias. Como hemos señalado en anteriores ocasiones, "el proceso electoral es por su propia naturaleza un procedimiento extremadamente rápido, con plazos perentorios en todas sus fases y tanto en su vertiente administrativa como en los recursos jurisdiccionales que se establecen para el control de la regularidad de todo el proceso. Tal naturaleza requiere en todos los partícipes una extremada diligencia, cuya falta determina la imposibilidad de alegar con éxito supuestas vulneraciones de derechos derivados del artículo 23 de la Constitución, que no habrían existido de mediar esa activa diligencia" (STC 67/1987, fundamento jurídico 2..$^{\circ}$ )" (f.j. 3).

Fallo: Denegar el amparo solicitado.

(Sentencia n. ${ }^{\circ} 73 / 1995$, de 12 de mayo. Sala Segunda. BOE 13-61995. F. García-Mon y González-Regueral).

5. Recurso de amparo electoral núm. 1.698/95, promovido por el Partido Popular contra Sentencia de la Sala de lo Contencioso-Administrativo del Tribunal Superior de Justicia de Aragón, de fecha 5 de mayo de 1995, por la que se desestimó el recurso promovido contra Acuerdo de la Junta Electoral de Zona de Zaragoza por el que se proclamaron las candidaturas del Partido Popular, para las elecciones municipales en el municipio de Fuentes de Ebro. Los demandantes de amparo entienden vulnerado su derecho a acceder en condiciones de igualdad a las funciones y cargos públicos al haberse desestimado su solicitud - presentada en el plazo de subsanación de errores-de alteración del orden de los candidatos una vez presentada la lista. El TC deniega el amparo.

«Para resolver el presente recurso ha de afirmarse, en primer término, que los derechos de participación reconocidos en el artículo 23 han de ejercerse en el marco establecido por la L.O.R.E.G., que los desarrolla y concreta, de modo que los límites establecidos en ella no pueden enervarse ni alterarse por la vía de la interpretación más favorable al derecho fundamental pues, si así fuera, quedaría en manos del intérprete, y no en las del legislador (a quien la Constitución, en sus artículos 53.1, 23.2 y 81.1, atribuye tal potestad) la fijación de los contornos del derecho. 
Esto sentado, el más somero análisis del artículo 48.1 de la L.O.R.E.G. pone de manifiesto que la renuncia del candidato titular, a la que se refiere dicho precepto, en cuanto se equipara al fallecimiento y desencadena la sustitución a que se refiere el número siguiente, no puede ser entendida sino como renuncia a figurar en la candidatura, sin que la renuncia al lugar que en ella se ocupa pueda ser, a fortiori, integrada en el precepto ni abra, por consiguiente, la posibilidad de subsanación.

Por lo tanto, y dado que la imposibilidad de alterar el orden de los candidatos una vez presentada la lista ni afecta al contenido esencial de los derechos fundamentales en juego ni resulta inconstitucional por ningún otro motivo, la resolución de este recurso no puede ser sino desestimatoria, cual la que ya dictó este Tribunal en la STC 61/1987, que contemplaba un supuesto idéntico» (f.j. único).

Fallo: Desestimar el presente recurso de amparo electoral.

(Sentencia n. ${ }^{\circ}$ 74/1995, de 12 de mayo. Sala Segunda. BOE 13-61995. T.S. Vives Antón).

6. Recurso de amparo electoral núm. 1.744/95, interpuesto por la coalición electoral "Esquerra Unida-Els Verds», contra la Sentencia que la Sección Primera de la Sala de lo Contencioso-Administrativo del Tribunal Superior de Justicia de la Comunidad Valenciana dictó el día 10 de mayo de 1995, que desestimó el recurso contencioso electoral sobre proclamación de candidatura presentada por la Coalición "Los VerdesGrupo Verde" para el municipio de Torrevieja (Alicante). El fundamento de la impugnación es la sedicente identidad de los símbolos utilizados por esta última coalición electoral y los propios de uno de los partidos políticos integrantres de la coalición electoral "Esquerra Unida-Els Verds", semejanza que, en su opinión, menoscaba los derechos fundamentales contenidos en los artículos 22 y 23.2 de la Constitución Española. El TC deniega el amparo.

«El examen comparativo de los símbolos de las dos candidaturas en oposición pone de manifiesto que ambas utilizan la expresión «Los Verdes" - una en valenciano y la otra en castellano-, no monopolizable por nadie según ha quedado dicho, con la representación idealizada de un girasol, que también ha ido generalizándose como símbolo de los movimientos ecologistas aquí y ahora. Una de las coaliciones en pugna le añade el propio de «Esquerra Unida», mientras que «Los Verdes-Grupo 
RESEÑA DE SENTENCLAS DEL TRIBUNAL CONSTTTUCIONAL SOBRE LA ADMINISTRACIÓN LOCAL...

Verde» prefieren las siglas «LV-GV». Estos elementos, en una visión global, revelan a su vez que el uno y el otro contienen factores distintivos suficientes para evitar el riesgo de confusión mutua que la Ley electoral proscribe, a diferencia de lo que pudo ocurrir hace años cuando al término "verde» aún no se le había atribuido en nuestro país el significado genérico que ha ido adquiriendo y, por ello, en aquel momento, esa distinta situación dio lugar a la solución que acoge la STC 107/1991. En definitiva, no se ha producido menoscabo alguno de los dos derechos fundamentales invocados, asociación y acceso a los cargos públicos en condiciones de igualdad (artículos 22 y 23.2 C.E.)» (vid. f.j. 2).

Fallo: Desestimar el presente recurso de amparo.

(Sentencia n. ${ }^{\circ}$ 75/1995, de 17 de mayo. Sala Segunda. BOE 21-61995. R. de Mendizábal Allende).

\section{ACTIVIDAD SANCIONADORA}

1. Recurso de amparo núm. 3.149/92, interpuesto contra la Sentencia de la Sala de lo Contencioso-Administrativo del Tribunal Superior de Justicia de Castilla y León, de 11 de noviembre de 1992, parcialmente estimatoria del recurso promovido contra el Decreto de la Alcaldía de León de 15 de marzo de 1989, que impuso al actor una sanción administrativa por una falta muy grave de desobediencia. El demandante de amparo denuncia la vulneración de sus derechos fundamentales a la presunción de inocencia y a no padecer indefensión reconocidos en el artículo 24.2 C.E., tanto en el procedimiento administrativo sancionador, como en el ulterior proceso jurisdiccional, pues en relación con la Sentencia, entiende que la Sala realiza una incorrecta selección de la normativa aplicable y que no tuvo presente los efectos de la nulidad de pleno Derecho del Decreto de la Alcaldia que previamente habia sido judicialmente declarada. El TC deniega el amparo.

«La traslación de la presunción de inocencia al ámbito administrativo sancionador perfila su alcance, y sólo cobra sentido cuando la Administración fundamenta su resolución en una presunción de culpabilidad del sancionado carente de elemento probatorio alguno. Cualesquiera otras incidencias acaecidas en la tramitación del expediente (ponderación por la Administración de los materiales y testimonios apartados, licitud de los mismos...) son cuestiones que, aunque pueden conducir a la declaración judicial de nulidad de la sanción por vicios o falta de garantí- 
as en el procedimiento (SSTC 68/1985 y 175/1987), en modo alguno deben incardinarse en el contenido constitucional del derecho a la presunción de inocencia, pues éste no coincide con las garantías procesales que establece el artículo 24.2 C.E., cuya aplicación al procedimiento administrativo-sancionador sólo es posible "con las matizaciones que resulten de su propia naturaleza» (STC 1 20/1994, fundamento jurídico $2 .^{\circ}$ ).

Lo mismo cabe decir respecto a la garantía constitucional de defensa en este contexto del procedimiento administrativo sancionador. Como declaró este Tribunal en la STC 18/1981, que inició una línea jurisprudencial posteriormente consolidada, «la garantía del orden constitucional exige que el acuerdo se adopte a través de un procedimiento en el que el presunto inculpado tenga oportunidad de aportar y proponer las pruebas pertinentes y alegar lo que a su derecho convenga".

En el presente caso, según se deduce del general de las actuaciones, quedó acreditado que el recurrente asumió el mando de la Jefatura de Policía sin contar con la pertinente autorización de sus superiores, lo que motivó la apertura del oportuno expediente sancionador. La acción sancionadora de la Administración, con independencia de su acierto en términos de legalidad ordinaria, se fundamentó en un elemento objetivo y contrastable, suficiente, por tanto, para enervar la presunción de inocencia en este ámbito de la potestad sancionadora de la Administración. A idéntica conclusión se llega respecto a la invocada lesión de su derecho a no padecer indefensión. La garantía de la asistencia letrada, como garantía constitucional conectada al derecho de defensa, no despliega su eficacia sobre los procedimientos administrativos, implicando la nulidad, por inconstitucional de lo en ellos actuado. Las exigencias constitucionales derivadas del artículo 24.2 C.E., se cumplen, como queda dicho, cuando la sanción es impuesta después de un procedimiento en el que se ofrece audiencia al administrado y se le permite hacer uso de medios de prueba y contradicción en la defensa de sus derechos e intereses. Todo ello, ha existido en el procedimiento administrativo del que ahora nos ocupamós, por lo que tampoco cabe apreciar lesión alguna del mencionado derecho fundamental» (vid. f.j. 2).

«No se debe olvidar que la Sentencia recurrida en este proceso constitucional estimó prácticamente todas las pretensiones del actor, manteniendo una única sanción por estimar la Sala que; a la luz del expediente y de las pruebas practicadas, sí había existido una falta de "grave desconsideración con los superiores». Resulta así, que el órgano judicial no confirmó la falta grave de desobediencia, sino que calificó la conducta del actor subsumiéndola en otro tipo sancionador de los legalmente previstos. En este extremo, resulta en todo punto capital lo declarado por la propia 
RESEÑA DE SENTENCIAS DEL TRIBUNAL CONSTITUCIONAL SOBRE LA ADMINISTRACIÓN LOCAL...

Sala en el fundamento jurídico décimo de su Sentencia: «... la Sala entiende que no se trata de una desobediencia muy grave, como sostiene el acto recurrido, dado que el señor L., obedece inicialmente la orden recibida, elabora el trabajo encomendado y cuando cree que el mismo ha sido cumplido se reincorpora a su cargo, si bien eso lo hace de manera incorrecta, sin esperar la confirmación de sus superiores, entendiendo este Tribunal (...) que sería aplicable al supuesto enjuiciado (...) la grave desconsideración con los superiores tipificada en el artículo 7.1 .c) como falta grave».

Con apoyo en esta argumentación, la Sala reducirá la sanción impuesta (de tres años de suspensión de funciones) a la de un año de suspensión de funciones. En todo caso, lo relevante para el enjuiciamiento del presente recurso de amparo, es que el órgano judicial no sancionó al actor por desobedecer la orden recibida y posteriormente declarada nula, sino por asumir el mando de la Jefatura de Policía sin esperar las instrucciones de la superioridad conducta autónoma y distinta de la primera, que la Sala, en su exclusiva función de valoración y calificación jurídica de los hechos, consideró como falta de desconsideración con los superiores, variando, así, la tipificación inicial de la conducta realizada por la Administración. Por consiguiente, el órgano judicial ni mantuvo la sanción por desobediencia a una orden judicialmente declarada nula, ni dejó de valorar el comportamiento eventualmente erróneo del recurrente, pues éste fue ponderado al determinar la proporcionalidad de la sanción definitivamente confirmada en su Sentencia.

Finalmente, aduce el demandante de amparo la lesión de su derecho a la tutela judicial efectiva por considerar que la Sala realizó una selección inadecuada de la normativa sancionadora de aplicación al caso. Reiteradamente ha declarado este Tribunal (por todas, STC 90/1990) que la selección e interpretación de la legalidad es competencia exclusiva de los Jueces y Tribunales ex artículo 117.3 de la C.E., por lo que, salvo en supuestos manifiestos de error patente -irracionabilidad o arbitrariedad-la opción seguida por los órganos judiciales no es susceptible de ser considerada como una lesión del derecho a la tutela judicial efectiva reconocido en el artículo 24.1 de la Constitución.

En virtud de lo anteriormente razonado, nada cabe objetar, desde la perspectiva de los derechos fundamentales invocados por el recurrente, a la Sentencia dictada por la Sala de lo Contencioso-Administrativo del Tribunal Superior de Justicia de Castilla y León, por lo que procede desestimar la presente demanda de amparo" (vid. f.j. 4).

Fallo: Denegar el amparo solicitado. 
(Sentencia n. ${ }^{\circ}$ 23/1995, de 30 de enero. Sala Segunda. BOE 28-21995. E. Díaz Eimil).

\section{VIVIENDA}

1. Conflicto de competencia núm. 81/1987, promovido por el Consejo Ejecutivo de la Generalidad de Cataluña en relación con el Convenio de financiación de operaciones de rehabilitación de viviendas de promoción pública, concertado entre el Director General de la Vivienda del Ministerio de Obras Públicas y Urbanismo y el Concejal-Presidente del Patronato Municipal de la Vivienda del Ayuntamiento de Barcelona, por entender que el citado convenio invade las competencias de la Comunidad Autónoma de Cataluña en materia de vivienda. El TC declara que la titularidad de la competencia de gestión controvertida corresponde a la Comunidad Autónoma de Cataluña.

"Una vez admitida la facultad estatal de intervenir en materia de vivienda amparándose en el artículo 149.1.13 CE, y no cuestionada la posibilidad de que el Estado ejerza esta competencia mediante la celebración de un Convenio de colaboración financiera con el Ayuntamiento de Barcelona, sólo debemos examinar si el Estado se ha extralimitado o no en el ejercicio de las competencias que le reconoce el artículo 149.1.13 $\mathrm{CE}$. Pues es obvio que, la mera invocación de este precepto no le autoriza a atraer hacia sí toda intervención, por penetrante que sea, en el sector objeto de la financiación estatal, por más que la misma se encuadre e nel ámbito de unas relaciones cooperativas establecidas con otro Ente que asimismo ostenta competencias en la materia.

A) En la abundante jurisprudencia constitucional vertida hasta la fecha acerca de las subvenciones condicionadas, cabe identificar ciertos criterios generales delimitadores de los respectivos ámbitos de atribuciones en supuestos de concurrencia competencial, como el presente, en que las facultades genéricas del Estado ex artículo 149.1.13 CE se superponen a las específicas sobre la materia financiada que atañen a las Comunidades Autónomas. En lo que aquí importa, dichas reglas establecen: $1^{\circ}$ ), que el Estado puede regular las condiciones esenciales de otorgamiento de las ayudas hasta donde lo permita su competencia general básica o de coordinación, pero siempre que deje un margen a las Comunidades Autónomas, al menos para desarrollar y complementar la regulación de las condiciones de otorgamiento de las ayudas y su tramitación. Y $2^{\circ}$ ), que la gestión de los fondos ha de corresponder, gene- 
RESEÑA DE SENTENCIAS DEL TRIBUNAL CONSTITUCIONAL SOBRE LA ADMINISTRACIÓN LOCAL...

ralmente, a las Comunidades Autónomas, lo que implica que deben ser distribuidos entre ellas conforme a criterios objetivos o mediante convenios, aunque cabe una gestión centralizada cuando resulte imprescindible para asegurar la plena efectividad de las ayudas dentro de la ordenación básica del sector, para evitar que se sobrepase la cuantía global de los fondos afectados y para garantizar iguales posibilidades de obtención y disfrute por parte de sus potenciales destinatarios en todo el territorio nacional (...)

B) Pues bien, en el escrito de planteamiento del conflicto la representación de la Generalidad no cuestiona las condiciones impuestas por el Convenio a los proyectos de construcción que aspiren a la financiación, sino el hecho de que se concentre en la Dirección General de la Vivienda del Ministerio de Obras Públicas todas las facultades de gestión sobre los recursos presupuestarios librados por el Estado. Y, en efecto, es a dicho órgano estatal a quien el Ayuntamiento de Barcelona debe presentar las promociones que pretendan acogerse a este régimen de ayudas -cláusula tercera-; ante el mismo debe justificar la adjudicación provisional de las obras para la firma de cada Convenio específico, así como presentar el correspondiente programa de ejecución - cláusula cuarta A) - y es, en fin, el órgano estatal aludido el encargado de abonar su parte de financiación al Patronato Municipal de la Vivienda del Ayuntamiento de Barcelona, y el competente para solicitar de éste cualquier información que considere conveniente para examinar el grado de cumplimiento del Convenio y el ritmo de las obras —cláusula cuarta $\mathrm{C}$ )—.

C) En el caso que ahora enjuiciamos, esta centralización de la gestión, con la subsiguiente marginación de la Comunidad Autónoma de la relación subvencional, no se compadece con las rígidas condiciones que, de acuerdo con la doctrina recién citada, deben satisfacerse para mantener excepcionalmente la gestión directa y centralizada de las ayudas que recaigan en materias respecto de las cuales el Estado se ha reservado solamente las bases y la Comunidad Autónoma ha asumido el resto de las funciones. Pues ni la necesidad de la gestión centralizada puede deducirse sin esfuerzo de la medida de fomento que ahora nos ocupa, ni dicha necesidad aparece razonablemente justificada -como pretende el Abogado del Estado- por la pretensión de evitar que se superen los topes máximos previstos en el Presupuesto del Estado para los fines del AES, o por la de asegurar la distribución homogénea de estos fondos en todo el territorio nacional. En consecuencia, cabe concluir afirmando que el Convenio impugnado, en la medida en que no atribuye a la Generalidad de Cataluña la gestión de las ayudas, ha desconoci- 
do el régimen competencial trazado por la Constitución y el Estatuto de Autonomía de Cataluña» (f.j. 5).

«Por último, es necesario precisar el alcance del fallo de la presente Sentencia que ha de limitarse a declarar la titularidad de la competencia de gestión controvertida, como así lo permite el artículo 66 de la Ley Orgánica de este Tribunal y hemos resuelto en otros supuestos similares (SSTC 79/1992 y 18/1994, entre otras). La anulación del abono directo de las subvenciones al Ayuntamiento de Barcelona podría suponer, en efecto, graves perjuicios y perturbaciones a los intereses generales, también en Cataluña, tanto por referirse el Convenio a ejercicios económicos ya cerrados y que han agotado sus efectos como por la necesidad de no afectar a legítimos derechos de terceros que se hayan generado con motivo de las subvenciones ya abonadas. En estas circunstancias, las pretensiones de la Generalidad de Cataluña pueden estimarse satisfechas mediante la declaración de la titularidad de la competencia de gestión aquí controvertida» (f.j. 6).

Fallo: Declarar que la titularidad de la competencia de gestión controvertida corresponde a la Comunidad Autónoma de Cataluña.

(Sentencia n. ${ }^{\circ}$ 59/1995, de 17 de marzo. Pleno. BOE 25-4-1995. J.D. González Campos).

\section{DERECHO PÚBLICO DE LA ECONOMÍA}

\section{A) Seguros}

1. Recurso de inconstitucionalidad núm. 2.061/92, interpuesto por el Consejo Ejecutivo de la Generalidad de Cataluña contra la Disposición adicional primera, en relación con diversos preceptos de la Ley 9/1992, de 30 de abril, de Mediación en Seguros Privados. El TC estima parcialmente el recurso.

"Dentro del Capítulo Cuarto de la Ley, se discute en la demanda el artículo 31 referido a los Colegios de Mediadores de Seguros Titulados, artículo que los define como Corporaciones de Derecho público dotadas de personalidad jurídica y a los que se incorporarán las personas físicas que voluntariamente lo deseen siempre que estén en posesión del diploma de Mediador de Seguros Titulado (apartado 1. ${ }^{\circ}$ ); y donde se señala que tendrán un ámbito territorial provincial y un Consejo General de 
RESEÑA DE SENTENCLAS DEL TRIBUNAL CONSTITUCIONAL SOBRE LA ADMINISTRACIÓN LOCAL...

ámbito nacional (apartado 6). En íntima relación con este artículo, la Disposición adicional tercera de la Ley -igualmente impugnada- ordena la transformación de los Colegios de Agentes y Corredores de Seguros y de su Consejo General en estos nuevos Colegios y Consejo, con idéntico ámbito territorial, personalidad jurídica y patrimonio, pero con distinta denominación y procediendo a su adaptación en el plazo de un año, debiendo celebrar elecciones democráticas tras la aprobación de los nuevos Estatutos colegiales.

Ya hemos visto que la mediación en seguros privados aunque se trate de una profesión sometida a autorización no configura una profesión titulada, pues no es necesario en ella título académico alguno y sí unas pruebas de aptitud conducentes a una capacitación oficial, aunque la representación de estos mediadores y la defensa de sus intereses corresponda a los Colegios de Mediadores de Seguros Titulados según este artículo 31. La nueva Ley ahora analizada, a diferencia del sistema anterior, hace la colegiación simplemente voluntaria en uso de la amplia libertad de configuración normativa que al legislador deja el artículo 36 de la Constitución y que, en concreto, ostenta respecto del carácter de la colegiación - forzosa o voluntaria - como requisito para el ejercicio de una profesión (SSTC 89/1989, fundamento jurídico $8 .^{\circ}$ y $131 / 1989$, fundamento jurídico $4 .^{\circ}$ ). En la primera de dichas Sentencias declaramos, respecto de los Colegios Profesionales, que el legislador pudo establecer la adscripción obligatoria «lícitamente, en razón de los intereses públicos vinculados al ejercicio de determinadas profesiones, como pudo no hacerlo si la configuración, esencia y fines de los Colegios fueran otros".

Así el artículo 31 , apartado $1 .^{\circ}$, de la Ley establece que las personas físicas que lo deseen se incorporarán voluntariamente a los Colegios y senala en su apartado $5 .^{\circ}$ que en ningún caso será requisito para el ejercicio de la actividad de corredor de seguros la incorporación a un Colegio, cualquiera que sea el ámbito territorial en que se pretenda ejercer la profesión. Por tanto, la imprescindible autorización administrativa (artículo 15), y el posterior régimen de control administrativo de esta profesión (artículo 24 y ss.) vienen a operar como sustitutivos de la antigua colegiación. De manera que el legislador -como dice la Exposición de Motivos- ha optado por un sistema de ejercicio profesional presidido por un marco de libertad en el mercado de seguros, pero sometido a autorización y al control del cumplimiento de ciertos requisitos y medidas cautelares, en vez de otorgar estas facultades disciplinarias a los Colegios y de erigir la colegiación en condición para el ejercicio profesional (algo que el artículo 31.5 de la Ley veda). Este cam- 
bio de regulación afecta a las condiciones esenciales de la conformación legal de los Colegios Profesionales que, como Corporaciones de Derecho público, están dentro del ámbito estatal propio de las bases de las Administraciones públicas (artículo 149.1.18), pese a la naturaleza privada de sus fines y cometidos principales (SSTC 76/1983, fundamento jurídico $43 .^{\circ}$, y $20 / 1988$, fundamento jurídico $\left.4 .^{\circ}\right)$. Unas bases a las que está sometida la competencia autonómica sobre Colegios profesionales ex artículo 9.23 del Estatuto de Cataluña.

Ahora bien, dado que en la Ley se limita considerablemente la dimensión pública que tenían estos Colegios, sustituyendo sus facultades de autorización y control por la que realicen los organismos competentes de la Administración Pública, paralelamente el nivel de lo básico ha de ser reducido y, por tanto, de la ordenación dispuesta en el artículo 31 sólo han de considerarse básicos, la denominación, la ausencia de obligatoriedad en su adscripción y la existencia de un Consejo General dado el ámbito nacional del mismo. A estos extremos ha de reducirse el mínimo denominador común para todo el territorio nacional, característico de unas normas básicas cuya competencia corresponde al Estado en virtud del artículo 149.1.18 de la Constitución; pero en todo lo demás la competencia corresponde a la Comunidad Autónoma de Cataluña en virtud de la competencia exclusiva que le atribuye el artículo 9.23 del Estatuto.

Interesa recordar que la Constitución no impone en su artículo 36 un único modelo de Colegio profesional. Bajo esta peculiar figura con rasgos asociativos y corporativos pueden englobarse por el legislador estatal, en ejercicio de su competencia para formalizar normas básicas de las Administraciones públicas ex artículo 149.1.18 de la Constitución, situaciones bien distintas como son las que corresponden al ejercicio de funciones públicas en régimen de monopolio o de libre concurrencia en el mercado como profesión liberal, y con colegiación forzosa o libre. Del mismo modo, no tiene por qué erigirse, en los supuestos legales de colegiación voluntaria, una inexistente obligación constitucional de colegiarse, en un requisito habilitante para el ejercicio profesional. Y es asimismo posible que los Colegios profesionales asuman la defensa de actividades profesionales que no configuren, en realidad, profesiones tituladas. Todos estos extremos pueden ser regulados libremente por el legislador estatal, desarrollando el artículo 36 , y con cobertura competencial en el artículo 149.1.18, ambos de la Constitución. Además, según dijimos en la STC 132/1989 (fundamento jurídico $7 .^{\circ}$ ), las excepciones al principio general de libertad de asociación han de justificarse, cuando se obligue al individuo a integrarse forzosamente en una agrupación 
RESEN̄A DE SENTENCIAS DEL TRIBUNAL CONSTTTUCIONAL SOBRE LA ADMINISTRACIÓN LOCAL...

de base asociativa, por la relevancia del fin público que se persigue, así como por la dificultad de obtener ese fin sin recurrir a la adscripción forzosa al ente corporativo.

Tampoco es ocioso traer a colación, para entender la razón a que la Ley responde, que, con fundamento en la libertad de establecimiento y de prestación de servicios, la Directiva del Consejo 77/92/CEE estableció unas medidas transitorias para prevenir posibles dificultades en el ejercicio de esas libertades respecto de las actividades de agente y corredor de seguros; partiendo del hecho de que en los distintos Estados miembros esas actividades profesionales se ven reguladas tanto por sistemas de libertad de acceso como por disposiciones rigurosas que prevén diplomas, para el acceso a la profesión. En este contexto, se insertan precisamente las previsiones del artículo 18 de la Ley sobre el régimen de acceso a la actividad de los nacionales de otros Estados miembros de la CEE.

Es, por otra parte, cierto a la luz de cuanto se viene diciendo que respetando los puntos de conexión y delimitación territorial de competencias establecidos en el apartado $2 .^{\circ}$ de la Disposición adicional primera, de los que ya nos hemos ocupado, así como las normas básicas formalizadas en esta Ley es posible -como ya dijimos- una intervención normativa en la materia por parte de la Generalidad de Cataluña en uso de su competencia asumida en el artículo 9.23 del Estatuto de Autonomía sobre Colegios Profesionales.

Y así se reconoce expresamente en el párrafo final del apartado $6 .^{\circ}$ del propio artículo 31 de la Ley en donde se afirma que las Comunidades Autónomas con competencias en este ámbito podrán con cargo a sus recursos propios, regular la creación fusión y extinción de Colegios de Mediadores de Seguros Titulados «de distinta extensión dentro de su propio ámbito territorial». Nada impide, por tanto, que la Generalidad regule la creación de Colegios en ámbitos territoriales diversos al provincial para aquellos mediadores que satisfagan los puntos de conexión establecidos en la Disposición adicional primera, apartado 2 . $^{\circ}$

Por tanto, reducida al mínimo la dimensión pública de los Colegios afectados resulta lógico que, como ya hemos dicho, el nivel de intervención estatal y, por tanto, el nivel de lo básico quede reducido a los extremos anteriormente indicados que son los únicos del artículo 31 de la Ley y de su disposición adicional tercera que ostentan tal carácter» (f.j.9). 
«Finalmente, el apartado $3 .^{\circ}$ de la Disposición adicional primera reserva al Estado en los supuestos del apartado anterior, y en todo caso, es decir, pese a la delimitación territorial de las competencias autonómicas en torno a sendos puntos de conexión que allí se efectúa, la concesión de la autorización administrativa para el ejercicio de la actividad de correduría de seguros y su revocación, esto es, las facultades que los artículos 15 y 19 de la Ley ordenan. Conviene recordar que, en esos supuestos, las demás competencias que la Ley atribuye al Estado y con excepción de éstas se entiende que corresponden a los órganos de las Comunidades Autónomas. El ejecutivo autonómico actor impugna este inciso final del citado apartado $3 .^{\circ} \mathrm{en}$ el cual la Ley reserva al Estado el otorgamiento de la autorización y su revocación, aduciendo que no pueden tener rango básico estas facultades de mera ejecución regladas por la propia Ley y en apoyo de su tesis invoca en la demanda el criterio sustentado en los Votos Particulares a la STC 86/1989.

El Abogado del Estado, quien asume la defensa de la Ley en este proceso, aduce que la excepcional reserva de facultades de ejecución en favor del Estado se justifica en que el otorgamiento de dicha autorización para ejercer la correduría de seguros implica efectuar unas apreciaciones de técnica aseguradora que exigen una interpretación unitaria las mismas razones que - a su juicio- en la STC 86/1989 llevaron a la mayoría del Tribunal a justificar la reserva al Estado de la autorización para ejercer la actividad aseguradora.

Sin embargo, no concurre en este caso como en aquél una justificación que quepa entender suficiente del siempre excepcional carácter básico de una norma que incorpora al ordenamiento jurídico potestades estatales de carácter ejecutivo en vez de las facultades normativas que habitualmente deben bastar para satisfacer las exigencias y finalidades a las que responde la previsión constitucional de normas básicas en el seno de las competencias compartidas entre el Estado y las Comunidades Autónomas (entre otras, SSTC 1/1982, fundamento jurídico 1. $25 / 1983$, fundamento jurídico $6 .^{\circ} ; 42 / 1983$, fundamento jurídico $5 .^{\circ}$; $57 / 1983$, fundamento jurídico $7 .^{\circ} ; 158 / 1986$, fundamento jurídico $3 .^{\circ}$; $49 / 1988$ fundamento jurídico $16 .^{\circ} ; 135 / 1992$, fundamento jurídico $5 .^{\circ} ; \mathrm{y}$ $168 / 1993$, fundamento jurídico $\left.5 .^{\circ}\right)$. Hay que entender, por tanto, que el apartado $3 .^{\circ}$, en su inciso final, de la Disposición adicional primera de la Ley recurrida, en virtud de la reserva de facultades al Estado que allí se efectúa, invade las facultades autonómicas de ejecución en materia de ordenación del seguro dispuestas en el artículo 10.1.4 del Estatuto de Cataluña, y que dentro de su territorio corresponden a la Generalidad. 
Es, sin duda, cierto -como aduce el Abogado del Estado- que en la STC 86/1989 [fundamento jurídico 13.a)] reconocimos que era constitucionalmente lícito que el Estado se reservase para sí la concesión de la correspondiente autorización administrativa $-\mathrm{y}$ su revocaciónpara el ejercicio de la actividad aseguradora en todo el territorio nacional e, incluso, en un ámbito menor cual es el propio de una Comunidad Autónoma, conforme al artículo 6.1 de la Ley de Ordenación del Seguro Privado. Pues, pese a tratarse de una actividad de ejecución, era inherente al juicio a efectuar para su otorgamiento una compleja apreciación financiera de las previsiones técnicas, según el artículo 24 de la misma Ley (riesgos en curso, capitales vencidos, rentas o beneficios de los asegurados pendientes de declaración de liquidación o pago, de desviación de siniestralidad, primas pendientes de cobro...), así como de la adecuación de las tarifas de primas a los principios de libertad de competencia, equidad y suficiencia según las reglas de la técnica aseguradora (artículo 23.3). La necesidad de que esa compleja apreciación técnica de conceptos tan indeterminados, con numerosos elementos valorativos, se interpretara de forma unitaria en todo el territorio nacional, incluido en ámbitos territoriales menores, evitando interpretaciones ccdiferenciadas y disfuncionales" para el mercado de seguros, nos llevó a declarar constitucional que el legislador estatal reservase a una instancia del Estado, en todo caso, la concesión de la autorización y de su revocación.

Mas, estas excepcionales circunstancias que justificaban allí la reserva -igualmente excepcional- de facultades de ejecución al Estado, con cobertura competencial en la formulación de bases, no concurren en la autorización administrativa para el ejercicio de la actividad (artículo 15 de la Ley) de correduría de seguros ni en su revocación (artículo 19). Pues no existe aquí ese complejo e indeterminado margen de apreciación técnica y valoración de elementos financieros que requiera, de manera inevitable, una interpretación unitaria por parte de los órganos generales del Estado con el fin de evitar resultados disfuncionales en el mercado nacional de seguros; y que justifique se excluya a las Comunidades Autónomas del normal ejercicio de sus competencias de ejecución dentro de su territorio. El papel de las Administraciones Públicas en la concesión de estas autorizaciones es una competencia reglada de ejecución con un escaso margen de discrecionalidad técnica, según se desprende de la lectura del artículo 15.2 de la Ley que fija los requisitos para ejercer la actividad de correduría de seguros" (vid. f.j. 10).

Fallo: Estimar en parte el recurso de inconstitucionalidad promovido por el Consejo Ejecutivo de la Generalidad de Cataluña contra las 
Disposiciones adicionales primera y tercera, en relación con diversos preceptos, de la Ley 9/1992: de 30 de abril, de Mediación en Seguros Privados $y$, en consecuencia:

1..$^{\circ}$ Declarar viciado de incompetencia y, por tanto, de inaplicación en Cataluña, el apartado $3 .^{\circ}$, inciso final de dicha Disposición adicional primera donde dice «quedando reservadas en todo caso al Estado la concesión, de la autorización administrativa para el ejercicio de la actividad de correduría de seguros y su revocación"; así como reconocer que la titularidad de las competencias en ese inciso ejercidas corresponde a la Generalidad de Cataluña.

2. Declarar viciados de incompetencia y, por tanto, de inaplicación en Cataluña, el artículo 31 y la Disposición adicional tercera de la Ley, relativos a los Colegios de Mediadores de Seguros Titulados, reconociendo que la competencia en tales normas ejercidas corresponde a la Generalidad de Cataluña, excepto en lo concerniente a su naturaleza y denominación, a la voluntariedad de la incorporación a los mismos y a la existencia de su Consejo General, extremos que han de considerarse básicos.

$3 .^{\circ}$ Desestimar el recurso en todo lo demás.

(Sentencia n. ${ }^{\circ}$ 330/1994, de 15 de diciembre. Pleno. BOE 18-1-1995. F. García-Mon y González-Regueral. Voto particular que formula C. Viver Pi Sunyer, al que se adhieren P. Cruz Villalón, y R. De Mendizábal Allende).

\section{B) Juegos y apuestas}

1. Recurso de inconstitucionalidad núm. 2.902/90 y en el conflicto positivo de competencia núm. 357/91, acumulados, promovidos ambos por el Gobierno de la Nación, y dirigido el primero contra la Ley del Parlamento de las Islas Baleares 12/1990, de 28 de noviembre, de Impuesto sobre las Loterías, y el segundo contra el Decreto del Consejo de Gobierno de las Islas Baleares 103/1990, de 13 de diciembre, por el que se aprueba el Reglamento que desarrolla aquella Ley. El TC estima el recurso y el conflicto y declara la nulidad de ambas disposiciones.

"Y, concretamente, en lo que al presente supuesto interesa los límites a la potestad tributaria de la Comunidad Balear, han de determinar- 
RESEÑA DE SENTENCIAS DEL TRIBUNAL CONSTITUCIONAL SOBRE LA ADMINISTRACIÓN LOCAL...

se en relación con la competencia sobre el monopolio de la Lotería Nacional derivada del artículo 149.1.14 CE, al objeto de determinar si aquélla ha podido desconocer, desplazar o limitar la del Estado en dicho monopolio, puesto que, como tiene declarado este Tribunal, es una exigencia evidente cuando se trata del ejercicio de la actividad de ordenación y gestión de los ingresos y gastos públicos en un Estado de estructura compuesta, que aquélla habrá de desarrollarse dentro del orden competencial...

Y teniendo aquí especialmente en cuenta que los límites de aquella potestad tributaria autonómica no quedan reducidos a los formulados expresamente en la L.O.F.C.A., artículos 6, 9 y 12, como tampoco a los que puedan derivarse de la configuración constitucional de la potestad tributaria del Estado y las Comunidades Autónomas en los párrafos 1 y 2 del artículo 133 de la Constitución. En el caso presente, la limitación establecida por los citados artículos 6.2 y 12.2 de la L.O.F.C.A. no quedaría reducida a la prohibición de no gravar los mismos hechos imponibles ya gravados por el Estado ni a configurar los recargos de modo que no puedan suponer una minoración de los ingresos del Estado o desvirtuar la naturaleza o estructura de los mismos (tal como subrayó también la STC 150/1990). Y no puede contemplarse según dichas normas porque aquí la Comunidad ha configurado un impuesto propio y no un recargo ni una participación en ingresos del Estado. Y por otra parte, la Lotería no es un impuesto estatal sino un monopolio fiscal de la Hacienda del Estado, integrado en el sistema de sus ingresos.

Por ello, en ese supuesto la potestad tributaria de la Comunidad balear debe entenderse afectada por otra limitación ya que el impuesto que ha configurado gravando "la participación en las loterías del Estado" (artículo 1) toma como hecho imponible la participación en los sorteos... mediante la adquisición de billetes, bonos o apuestas, con lo cual el objeto impositivo resulta ser el mismo objeto económico del monopolio, constituido por la participación de los individuos en aquellos sorteos, que es lo que nutre todos los fondos del monopolio tanto en cuanto a premios o gastos de gestión propios como, fundamentalmente, a los ingresos para la Hacienda. Y al gravar la adquisición de billetes, además de gravarse un efecto estancado cuyo tráfico ordinario no está permitido (artículo 2 del Decreto de 23 de marzo de 1956) se está gravando el mismo objeto y la misma fuente de recursos de aquél. Con ello, influya o no el encarecimiento de los billetes o las apuestas en el volumen de ingresos, lo fundamental es que las participaciones quedan sometidas a un impuesto autonómico sólo dependiente de la potestad de la Comunidad en toda su regulación (incluso los tipos impositivos) determinan- 
do que de dicha potestad autonómica puedan pasar a depender en gran medida los rendimientos de las loterías. Lo cual evidencia la clara invasión de este impuesto en lo que constituye objeto propio del monopolio fiscal de competencia del Estado» (vid. f.j. 4).

"Aun siendo cierto, como afirma el Abogado de la Comunidad Autónoma, que el impuesto establecido no grava la organización por el Estado de sorteos de la Lotería Nacional sino la actividad del particular participante en los mismos, esa actividad participativa, bien mediante la adquisición de billetes o fracciones en el caso de la Lotería Nacional, bien mediante la de los boletos para la realización de apuestas en el supuesto de la Lotería Primitiva o de la Bono-Loto, es, repetimos, la generadora de los rendimientos del monopolio, o sea, la fuente misma de la que proceden los recursos obtenidos de su directa explotación que son derechos económicos de la Hacienda del Estado. Los rendimientos del monopolio de la Lotería Nacional, cuya explotación ha asumido exclusivamente el Estado para generarlos mediante la participación de los ciudadanos en los sorteos de sus Loterías no proceden de la mera organización estatal de dichos sorteos, sino, como antes decimos precisamente, de la participación de los ciudadanos en los mismos y por ello resultan inescindibles el aspecto organizativo y el participativo.

Por consiguiente, la ley autonómica impugnada, y en consecuencia el Reglamento que la desarrolla, al establecer un impuesto sobre la participación en los sorteos de Lotería del Estado, no sólo perjudica y limita, como sostiene el Abogado del Estado, la obtención del recurso en que la Lotería Nacional consiste, sino que toma por objeto impositivo que somete a gravamen la misma actividad productora de ingresos o recursos para la Hacienda estatal ejercida como explotación de un monopolio fiscal del Estado. De este modo, no sólo invade o menoscaba la competencia que a aquél atribuye sobre el monopolio el artículo 149.1.14 de la C.E., sino que, como antes señalamos, hace depender sus ingresos de la potestad autonómica sobre el impuesto creado.

En consecuencia, debemos estimar el recurso de inconstitucionalidad por este motivo formulado. Lo cual hace innecesario entrar en el examen de la segunda de las cuestiones suscitadas y determina, no sólo la nulidad de la Ley impugnada, sino también la del Reglamento objeto del conflicto de competencia, en el cual igualmente se pretendía dicha declaración. Lo que, por otra parte, hace innecesario un pronunciamiento acerca de la atribución de competencia» f.j. 5). 
RESEÑA DE SENTENCIAS DEL TRIBUNAL CONSTTTUCIONAL SOBRE LA ADMINISTRACION LOCAL...

Fallo: Estimar el recurso de inconstitucionalidad y el conflicto positivo de competencia, y en consecuencia, declarar la inconstitucionalidad y consiguiente nulidad de las dos disposiciones impugnadas.

(Sentencia n. ${ }^{\circ}$ 49/1995, de 16 de febrero. Pleno. BOE 18-3-1995. J. Gabaldón López).

\section{EDUCACIÓN}

1. Cuestión de inconstitucionalidad núm. 710/94 planteada por la Sección Tercera de la Sala Tercera del Tribunal Supremo en relación con los artículos 14.2 y 4, 15 (inciso primero) y 20 de la Ley 7/1983, de 18 de abril, del Parlamento de Cataluña, sobre Normalización Lingüistica. El TC declara constitucionales los artículos 14.2, 14.4 y 20, así como que el artículo 15 no es inconstitucional interpretado en el sentido expuesto en el fundamento jurídico 18.

«Entrando ya en el enjuiciamiento del primero de los preceptos impugnados, el artículo 14.2 de la Ley 7/1983, de 18 de abril, del Parlamento de Cataluña, dispone lo siguiente: «Los niños tienen derecho a recibir la primera enseñanza en su lengua habitual, ya sea ésta el catalán o el castellano. La Administración debe garantizar este derecho y poner los medios necesarios para hacerlo efectivo. Los padres o los tutores pueden ejercerlo en nombre de sus hijos instando a que se aplique».

Para el órgano judicial que promueve la cuestión, si este precepto no es inútil, pues únicamente se refiere a la primera etapa de la enseñanza, sólo puede tener una interpretación coherente: que los niños carecen del derecho a recibir enseñanza en su lengua habitual en las posteriores etapas educativas. De donde resultaría que ésta es una materia disponible para los poderes públicos, los que podrían imponer por ley que se reciba la enseñanza en una lengua distinta de la oficial del Estado y respecto a la que no existe el deber constitucional de conocerla. Por lo que el artículo 14.2 de la Ley puede ser contrario al artículo 3.1 y 2 C.E. así como a los artículos $1.1,9.2,10,15$ y 27.2 y 5 de la Norma fundamental, preceptos constitucionales que han de constituir el canon pára nuestro enjuiciamiento» (f.j. 5).

«La Ley 7/1983, del Parlamento de Cataluña, en cuanto sirve al objetivo de normalización lingüística del artículo 3 del E.A.C., ha pretendido fundamentalmente fomentar la utilización del catalán, lengua propia de 
Cataluña, como «lengua de la enseñanza en todos los niveles educativos» (artículo 14.1). Pero también cabe observar, en contrapartida, que ninguna disposición de dicha Ley excluye el empleo del castellano como lengua docente. Y al respecto ha de tenerse presente que en la STC 6/1982, fundamento jurídico $10 .^{\circ}$, hemos dicho tempranamente que corresponde al Estado velar por el respeto de los derechos lingüísticos en el sistema educativo y, en particular, «el de recibir enseñanza en la lengua oficial del Estado"; pues no cabe olvidar que el deber constitucional de conocer el castellano (artículo 3.1 C.E.) presupone la satisfacción del derecho de los ciudadanos a conocerlo a través de las enseñanzas recibidas en los estudios básicos. De este modo, las instituciones autonómicas, dentro del marco competencial en materia de educación que establecen los artículos 149.1.30 C.E. y 15 E.A.C., han podido establecer en la mencionada Ley 7/1983, de 18 de abril, en desarrollo de la legislación básica del Estado, un régimen de la enseñanza en el que el catalán y el castellano no sólo son materia objeto de estudio sino lengua docente en los distintos niveles educativos. Y ello con la finalidad, como antes se ha dicho, de que todos los estudiantes en Cataluña "cualquiera que sea su lengua habitual al iniciar la enseñanza», puedan "utilizar normal y correctamente el catalán y el castellano al final de sus estudios básicos» (artículo 14.4 de la Ley).

Este modelo de conjunción lingüística que inspira la Ley $7 / 1983$, del Parlamento de Cataluña, es constitucionalmente legítimo en cuanto responde a un proposito de integración y cohesión social en la Comunidad Autónoma, cualquiera que sea la lengua habitual de cada ciudadano. Al igual que es legítimo que el catalán, en atención al objetivo de la normalización lingüística en Cataluña, sea el centro de gravedad de este modelo de bilingüismo, siempre que ello no determine la exclusión del castellano como lengua docente de forma que quede garantizado su conocimiento y uso en el territorio de la Comunidad Autónoma. Si al término de los estudios básicos los estudiantes han de conocer suficientemente y poder usar correctamente las dos lenguas cooficiales en Cataluña (artículo 14.4 de la Ley), es evidente que ello garantiza el cumplimiento de la previsión del artículo 3.1 C.E. sobre el deber de conocimiento del castellano, al exigirse en dichos estudios no sólo su aprendizaje como materia curricular sino su empleo como lengua docente (STC 6/1982). De otro, al ser el catalán materia curricular y lengua de comunicación en la enseñanza, ello asegura que su cooficialidad se traduzca en una realidad social efectiva; lo que permitirá corregir situaciones de desequilibrio heredadas históricamente y excluir que dicha lengua ocupe una posición marginal o secundaria (...)

En definitiva, a la luz de lo expuesto cabe estimar que el artículo 14.2 de la Ley de Normalización Lingǘstica en Cataluña no resulta contra- 
RESEÑA DE SENTENCIAS DEL TRIBUNAL CONSTTTUCIONAL SOBRE LA ADMINISTRACIÓN LOCAL...

rio a los artículos 3 y 27 C.E. En primer lugar, porque no contradice la normativa básica del Estado, cuya constitucionalidad no es discutida en el Auto de planteamiento de la cuestión. Además, porque en esta normativa el legislador autonómico ha ponderado las exigencias derivadas de los mandatos constitucionales y estatutarios atinentes a la garantía del conocimiento del castellano y del catalán, lenguas cooficiales en $\mathrm{Ca}$ taluña. Regulación que en ningún momento ha sido considerada -ni por las partes en el proceso a quo ni por el Auto de planteamiento de la cuestión - como obstativa, impeditiva o simplemente contraria a la garantía de conocimiento suficiente de las lenguas catalana y castellana al término de la ensenanza básica. Finalmente, porque el precepto autonómico cuestionado de ningún modo entraña la exclusión de una de las dos lenguas cooficiales en los niveles posteriores a la "primera enseñanza" como lengua docente; pues la Ley del Parlamento de Cataluña ha previsto, por el contrario, el uso de ambas lenguas y la utilización de la lengua catalana de forma progresiva, como se desprende del artículo 14.5 b) de la misma.

En suma, de lo anterior claramente se desprende que corresponde a los poderes públicos competentes, en atención a los objetivos de la normalización lingüística en Cataluña y a los propios objetivos de la educación, organizar la enseñanza que ha de recibirse en una y otra lengua en relación con las distintas áreas de conocimiento obligatorio en los diferentes niveles educativos para alcanzar un resultado proporcionado con estas finalidades; y ello al objeto de garantizar el derecho de los ciudadanos a recibir, durante los estudios básicos en los Centros docentes de Cataluña, enseñanza en catalán y en castellano. Derecho que se deriva no sólo de los artículos 3 y 27 C.E. sino del artículo 3 del E.A.C.» (vid. f.j. 10).

"Aunque no exista un derecho a la libre opción de la lengua vehicular de enseñanza, ello no implica que los ciudadanos carezcan de derecho alguno frente a los poderes públicos desde la perspectiva del derecho a la educación que el artículo 27 a todos garantiza. Máxime si las actuaciones de normalización lingüística vienen a incidir sobre un presupuesto tan esencial a dicho derecho fundamental como es la lengua en la que ha de impartirse la educación.

En efecto, aun cuando la finalidad a alcanzar sea el dominio de la lengua castellana y de la lengua propia de la Comunidad Autónoma al término de los estudios, es evidente que quienes se incorporan al sistema educativo en una Comunidad Autónoma donde existe un régimen de cooficialidad lingüística han de recibir la educación en una lengua en la 
que puedan comprender y asumir los contenidos de las enseñanzas que se imparten; ya que en otro caso podrían quedar desvirtuados los objetivos propios del sistema educativo y afectada la plenitud del derecho a la educación que la Constitución reconoce. En particular y desde la perspectiva del artículo 27 C.E., pero también desde la relativa al artículo 14 C.E., resulta esencial que la incorporación a la enseñanza en una lengua que no sea la habitual se produzca bajo el presupuesto de que los ciudadanos hayan llegado a dominarla, cuando menos en la medida suficiente para que su rendimiento educativo no resulte apreciablemente inferior al que hubieran alcanzado de haber recibido la enseñanza en su lengua habitual.

La Ley catalana 7/1983 de 18 de abril, responde plenamente a estas exigencias por cuanto su artículo 14.2 garantiza el derecho a iniciar la incorporación al sistema educativo en la lengua habitual; a la vez que prescribe medidas para que la lengua catalana «sea utilizada progresivamente a medida que todos los alumnos la vayan dominando" [artículo $14.5 \mathrm{~b})$ ].

Por ello al determinar la utilización de la lengua propia de la Comunidad como lengua docente, los poderes autonómicos deben ponderar adecuadamente la consecución de aquella finalidad atendiendo tanto al proceso de formación de la personalidad de los estudiantes en los sucesivos niveles del sistema educativo como a la progresividad inherente a la aplicación de dicha nedida. Pues en relación con el presente caso cabe observar que aun siendo constitucionalmente legítima la opción del legislador catalán en favor de un modelo de conjunción o integración lingüística, con sus innegables beneficios para la integración social, no es menos cierto, sin embargo, que los objetivos de dicho modelo no pueden ser alcanzados de forma inmediata o aceleradamente. Consecuentemente, ello exige que los poderes autonómicos, para lograr la plena adaptación e integración de los estudiantes al sistema educativo, han de ofrecerles los medios de apoyo pedagógico adecuados que faciliten, tanto en el ciclo inicial de los estudios no universitarios como en los posteriores, el previo conocimiento de la lengua cooficial en la Comunidad Autónoma distinta del castellano.

De otro lado, respecto a quienes ya han cursado estudios en una Comunidad Autónoma donde sólo el castellano es materia obligatoria y pasan a integrarse en los Centros educativos de otra Comunidad donde existe un régimen de cooficialidad lingüística, del mencionado principio se deriva una exigencia adicional para los poderes autonómicos: la de establecer medidas de carácter flexible en la ordenación legal de las en- 
RESEÑA DE SENTENCIAS DEL TRIBUNAL CONSTITUCIONAL SOBRE LA ADMINISTRACION LOCAL...

señanzas para atender estas especiales situaciones personales. Pues, de lo contrario, es claro que podría quedar afectada la continuidad de los estudios en todo el territorio del Estado por razón de la lengua, con evidente vulneración del derecho a la educación garantizado por el artículo 27 de nuestra Norma fundamental» (f.j. 11).

«El Tribunal Supremo cuestiona asimismo la legitimidad constitucional del artículo 14.4 de la Ley 7/1983, de 18 de abril, del Parlamento de Cataluña en cuya virtud "Todos los niños de Cataluña, cualquiera que sea su lengua habitual al iniciar la enseñanza, deben poder utilizar normal y correctamente el catalán y el castellano al final de sus estudios básicos». Para el Alto Tribunal resulta dudosa la constitucionalidad del precepto ya que éste no es una admonición a los poderes públicos para que promuevan, sin violación de los derechos constitucionales, las condiciones necesarias para conseguir el fin enunciado, sino que puede contener la imposición a los niños de un deber («deben conocer»): el de conocer una lengua oficial distinta a la del Estado. Lo que se entiende que podría ser contrario al artículo 3.1 y 2 C.E. y, asimismo, al principio o valor superior de la libertad del artículo 1.1 del Texto fundamental, que se vería limitada y coaccionada con tal imposición" (vid. f.j. 13).

«Entrando ya en el enjuiciamiento del precepto impugnado, cabe observar que si se relacionan los apartados 3 y 4 del artículo 14 de la Ley del Parlamento de Cataluña, fácilmente se llega a la conclusión, en primer lugar, que el precepto cuestionado es una norma de carácter finalista, que establece un objetivo a alcanzar en el desarrollo de las capacidades a que deben contribuir los estudios básicos, a saber: que todos los estudiantes, al término de estos estudios, puedan utilizar normal y correctamente ambas lenguas oficiales en Cataluña. Finalidad que también se contiene, con el carácter de normas básicas, en los artículo 13 a) y 19 a) L.O.G.S.E., preceptos donde se establecen, respectivamente, entre los objetivos de la "educación primaria», la aptitud de los niños para «utilizar de manera apropiada la lengua castellana y la lengua oficial propia de la Comunidad Autónoma»; y entre los fines de la educación secundaria obligatoria, "comprender y expresar correctamente en lengua castellana y, en la lengua de la Comunidad Autónoma, textos y mensajes complejos, orales y escritos».

De otra parte, ha de tenerse en cuenta que el precepto se dirige a quienes han cursado los estudios básicos en Cataluña, como ha señalado el Fiscal del Estado. De suerte que lo dispuesto en el artículo 14.3 -la enseñanza obligatoria de ambas lenguas oficiales en todos los niveles y grados constituye el presupuesto necesario para alcanzar el objetivo del 
artículo 14.4. Y cuando tal presupuesto no se da, por haber cursado el niño la enseñanza general básica fuera del territorio de Cataluña y no conocer la lengua catalana, el segundo inciso del artículo 15 de la Ley 7/1983 hace posible la no exigencia de la acreditación del conocimiento de esta lengua; lo que claramente excluye la imposición de un deber a los estudiantes, al no existir una contradicción con el anterior desarrollo de las enseñanzas que se han cursado.

Por tanto, ha de llegarse a la conclusión de que el artículo 14.4 de la Ley $7 / 1983$, de 18 de abril, no infringe el artículo 3.1 y 2 C.E. Ni tampoco cabe entender que pueda lesionar el artículo 1.1 de la Norma fundamental, por sí sólo o en conjunción con los mencionados, por las razones ya expuestas en el fundamento jurídico 12» (f.j. 15).

«El tercer precepto que hemos de enjuiciar es el artículo 15 de la Ley $7 / 1983$, de 18 de abril, del que sólo se cuestiona la conformidad con la Constitución de su primer inciso, a tenor del cual «no se puede expedir el certificado de grado de la enseñanza general básica a ningún alumno que, habiendo empezado esta enseñanza después de publicada la presente Ley, no acredite al terminarla que tiene un conocimiento suficiente del catalán y del castellano».

Para el Tribunal Supremo, la conexión del precepto con el artículo 2.1 del Decreto 362/1983 es indudable, por ser éste una reproducción casi literal de aquél. De otra parte, la duda sobre su inconstitucionalidad respecto al artículo 3.1 y 2 C.E. se suscita por no imponer este precepto, ni los Estatutos de Autonomía, el deber de conocer la lengua oficial en una Comunidad Autónoma distinta del castellano, lengua oficial del Estado; en relación con el artículo 149.1.1 C.E., pues ciertos derechos, como el de acceso a cargos públicos del artículo 23.2 C.E. puede depender de la obtención del título de Graduado Escolar; en lo que concierne al artículo 149.1.30 de la Norma fundamental, por cuanto este precepto reserva en exclusiva al Estado a "regulación de las condiciones de obtención, expedición y homologación de títulos académicos y profesionales» y, asimisnio, respecto al 139.1 C.E., por prescribir el precepto impugnado una obligación inexistente en otras Comunidades Autónomas donde existen dos lenguas oficiales" (vid. f.j. 16).

"Desde una perspectiva estrictamente competencial; el Tribunal Supremo considera, de un lado, que el precepto cuestionado puede vulnerar el artículo 149.1.1 C.E., pues de la posesión del título de Graduado Escolar puede depender el derecho de acceso a cargos públicos (artículo 23.2 C.E.). De otro lado, que si el artículo 149.1.30 C.E. reserva en ex- 
RESEÑA DE SENTENCIAS DEL TRIBUNAL CONSTITUCIONAL SOBRE LA ADMINISTRACION LOCAL...

clusiva al Estado «la regulación de las condiciones de obtención, expedición y homologación de títulos académicos", - y el de Graduado Escolar al que se refiere el precepto impugnado es uno de ellos- la Comunidad Autónoma no puede establecer en qué condiciones se puede expedir y a quiénes dicho título. Señalando al respecto que en nuestra STC 123/1988 ya se declaró la inconstitucionalidad de un precepto sustancialmente idéntico al aquí cuestionado, el artículo 20.2 de la Ley 3/1986, de 26 de abril, de Normalización Lingüística de la Comunidad Autónoma de las Islas Baleares.

Sin embargo, en relación con el primer reproche una precisión es necesaria. En realidad, la posible quiebra del principio de igualdad que el Alto Tribunal conecta con el artículo 23.2 C.E. deriva de la exigencia de un "conocimiento suficiente del catalán» establecido por el primer inciso del artículo 15 de la ley de Normalización Lingüística en Cataluña para la expedición del título de Graduado Escolar. De suerte que la conclusión sobre la eventual vulneración del artículo 149.1.1 C.E. se halla condicionada por la que alcancemos respecto a la invasión competencial que también se denuncia con fundamento en el artículo 149.1.30 C.E.; pues sólo si el precepto impugnado vulnerase el artículo 149.1.30 C.E. podría estimarse que también lesiona las condiciones básicas que garantizan la igualdad de todos los españoles en el ejercicio del derecho de acceso a los cargos públicos. Por lo que necesariamente hemos de examinar con carácter previo la duda expuesta en relación con este último precepto constitucional ( ... )

Cabe entender, pues, que la finalidad del primer inciso del artículo 15 de la Ley catalana $7 / 1983$, está íntimamente unida en un iter temporal a lo establecido en el artículo 14.4 de la propia Ley, pues, si con posterioridad a la entrada en vigor de la Ley $7 / 1983$, los alumnos han de cursar "obligatoriamente» en los Centros docentes de Cataluña las dos lenguas oficiales de dicha Comunidad, durante la E.G.B., con la finalidad de que al término de los estudios básicos aquellos puedan utilizar "normal y correctamente» el catalán y el castellano, es claro que los estudiantes habrán acreditado poseer un conocimiento suficiente de ambas lenguas y, de este modo, cumplen las condiciones que la Ley estatal establece para la obtención del título de Graduado Escolar. Por lo que el precepto puede ser interpretado en el sentido de que no añade una nueva condición ni modifica la establecida en la legislación del Estado, sino que integra esa legislación en relación al contenido de los estudios; y ello en el marco de las competencias que corresponden a la Comunidad Autónoma, tratando de asegurar, en el momento de la expedición del certificado de Graduado Escolar, el logro del objetivo es- 
tablecido en el artículo 14 de la Ley, en relación a la obligatoriedad de la enseñanza de ambas lenguas. Interpretación que se corrobora con lo previsto en el inciso segundo del artículo 15, que se refiere a quienes han sido dispensados de aprender el catalán o no lo han aprendido por haber «cursado la Enseñanza General Básica fuera del territorio de Cataluña». De manera que el precepto también puede ser considerado como el recordatorio del presupuesto legal de haber cursado con suficiente aprovechamiento una y otra lengua como materias obligatorias en los Centros docentes de Cataluña.

Así interpretado, el primer inciso del artículo 15 de la Ley 7/1983, de 18 de abril, no vulnera la competencia que el artículo 149.1.30 C.E. reconoce al Estado» (vid. f.j. 18).

«Finalmente, el Tribunal Supremo duda de la conformidad con la Constitución del artículo 20 de la Ley de Normalización Lingüística de Cataluña, que dice así: "Los Centros de Enseñanza deben hacer de la lengua catalana vehículo de expresión normal tanto en las actividades internas, incluyendo las de carácter administrativo, como en las de proyección externa».

Según el Alto Tribunal —que interpreta el alcance del precepto cuestionado a partir de su desarrollo en los apartados 2 y 5 del artículo 13 del Decreto 362/1983 - es legítimo hacer de la lengua catalana vehículo de expresión normal con otros Centros y con las Administraciones públicas del territorio. Pero respecto a las relaciones con los padres y estudiantes, el precepto entraña, por constituir la lengua catalana el «vehículo de expresión normal" del Centro; que la lengua castellana quede relegada al puesto de secundaria o accesoria pese a ser la oficial del Estado y la única que no puede ser desconocida; pues no se prescribe que los horarios de enseñanzas comunicados y avisos en los tablones de anuncios y rótulos de las dependencias del Centro se redacten en catalán y castellano, ni se permite que los interesados puedan solicitar que se hagan también en castellano. Por lo que esta virtual exclusión del castellano, a su juicio, puede ser contraria a los artículos 3.1 y $2,9.2,14$ y 27.2 C.E.

Pasando ya a examinar la conformidad con el artículo 3.1 y 2 C.E. del precepto cuestionado - al que hemos de ceñir nuestro examen, con exclusión de las disposiciones reglamentarias de desarrollo, por lo expuesto en el fundamento jurídico $3 .^{\circ}-$ desde la perspectiva constitucional ningún reproche puede merecer que en los Centros docentes radicados en Cataluña la lengua catalana haya de ser vehículo de ex- 
RESENA DE SENTENCIAS DEL TRIBUNAL CONSTTTUCIONAL SOBRE LA ADMINISTRACIÓN LOCAL...

presión «normal» tanto en las actividades internas como en las de proyección exterior (...) El significado del precepto impugnado, considerado en sí mismo y en el contexto de la Ley $7 / 1983$, no entraña en modo alguno que el catalán haya de ser utilizado como lengua única en las relaciones de los ciudadanos con los Centros docentes situados en Cataluña, ni en las de éstos con aquéllos, con el consiguiente desconocimiento o exclusión del castellano. Pues hemos declarado que en los territorios dotados de un estatuto de cooficialidad lingüística, los particulares pueden emplear cualquiera de las lenguas oficiales, a su elección, «en las relaciones con cualquier poder público radicado en dicho territorio, siendo el derecho de las personas al uso de una lengua oficial un derecho fundado en la Constitución y el respectivo Estatuto de Autonomía» (STC 82/1986, fundamento jurídico 3. ); facultad de elección que se reconoce expresamente en el artículo 8.1 de la Ley de Normalización Lingüística en Cataluña y que no se desconoce en el precepto cuestionado, no sólo por la necesaria conexión entre ambos preceptos de la misma Ley, sino también porque el adjetivo "normal» que utiliza el artículo 20 excluye la idea de deber o imposición que justificaría la duda sobre su constitucionalidad. El mandato que contiene el artículo 20 de la Ley 7/1983, de 18 de abril, no resulta, pues, incompatible con el carácter cooficial del castellano en la Comunidad Autónoma de Cataluña, ni con el derecho a usarlo por quienes mantengan cualquier tipo de relación con los Centros docentes allí situados, ya se trate de los alumnos o de sus padres y familiares. Por lo que ha de estimarse que el artículo 20 de la Ley 7/1983, de 18 de abril, no es contrario al artículo 3.1 y 2 C.E.

De otra parte, no se llega a una conclusión distinta del contraste de dicho precepto constitucional en conjunción con los artículos 9.2 y 14 C.E. Aun teniendo la Ley aquí considerada como objetivo principal la normalización del uso de la lengua catalana en todos los ámbitos, no cabe olvidar que también está dirigida a "garantizar el uso normal y oficial del catalán y del castellano" (artículo 1.1 de la Ley, con referencia al artículo 3 del E.A.C.); y los particulares, como se acaba de indicar, pueden utilizar la lengua de su elección en sus relaciones con los Centros educativos. Por lo que no cabe entender que el precepto cuestionado sea contrario al derecho de igualdad que la Constitución reconoce ni al mandato de promover las condiciones para que la igualdad sea efectiva (artículo 9.2 C.E.). Resultado negativo al que también conduce el contraste del precepto cuestionado con el artículo 27.2 C.E., ya que no cabe considerar que el uso normal y habitual del catalán en las actividades de los Centros docentes dé lugar a la creación de un uentorno idiomático forzado" y distinto del familiar que pueda afectar al pleno 
desarrollo de la personalidad humana como objetivo del derecho constitucional a la educación. Pues basta observar que si el catalán es lengua cooficial en Cataluña y lengua usual en la sociedad catalana, difícilmente cabe imputar al Centro docente, en atención al uso normal y habitual del catalán, la creación de un entorno que no es distinto al de la propia sociedad a la que sirve» (ff.jj. 20 y 21 ).

Fallo: $10^{\circ}$ Declarar que los apartados 2 y 4 del artículo 14 , así como el artículo 20 de la Ley 7/1983, de 18 de abril, del Parlamento de Cataluña, no son contrarios a la Constitución.

2. Declarar que el primer inciso del artículo 15 de la antedicha Ley 7/1983, de 18 de abril, del Parlamento de Cataluña no es inconstitucional interpretado en el sentido expuesto en el fundamento jurídico 18.

(Sentencia n. ${ }^{\circ}$ 337/1995, de 23 de diciembre. Pleno. BOE 23-1-1995. J.D. González Campos. Votos particulares que formulan, el primero, E. Díaz Eimil, y el segundo, J. Gabaldón López).

\section{SANIDAD}

1. Conflicto positivo de competencia núm. 1.218/86, promovido por la Junta de Galicia en relación con los artículos 2.1, núms. 1.3 , y 1.5; artículo 4, párrafo $1 .^{\circ}$, artículo 4.4, núms. 1,2 y 3; artículo 4.5; artículo 7.1 [y en conexión con él, artículo 2.1, núm. 4 b)], y artículo 12, del Real Decreto 1.418/1986, de 13 de junio, sobre funciones del Ministerio de Sanidad y Consumo en materia de Sanidad Exterior, y demás preceptos del mismo por conexión directa o causal con los mencionados, en cuanto regulan materias que afectan a la titularidad competencial de la Comunidad Autónoma de Galicia. El TC entiende que no existe vulneración de competencias autonómicas.

«Dichos preceptos impugnados, con el contenido que se acaba de precisar, deben ser confrontados, en primer lugar, con la atribución de competencia exclusiva que la Constitución realiza a favor del Estado en materia de sanidad exterior (artículo 149.1.16), atribución que es plena y alcanza tanto a la normación como a la ejecución, de modo que toda competencia que pueda ser encuadrada directamente en dicho título pertenece indubitadamente al Estado (STC 252/1988, fundamento jurídico $3 .^{\circ}$ ). 
RESEÑA DE SENTENCIAS DEL TRIBUNAL CONSTTTUCIONAL SOBRE LA ADMINISTRACIÓN LOCAL...

Junto a ello, debe considerarse que pertenece a la Comunidad Autónoma de Galicia el desarrollo legislativo y la ejecución de la legislación básica del Estado en materia de sanidad interior (artículo 33.1 EA.G.), de modo que es la distinción entre el aspecto interior o exterior de la actividad pública en materia sanitaria lo que debe servir de guía para determinar la titularidad de la competencia disputada. Al ser ambos aspectos especificación del concepto genérico de sanidad, en cuanto definitorio de una actividad desarrollada por las distintas administraciones, no es precisa una clara definición de éste, sino simplemente determinar si la competencia a la que se refieren las normas impugnadas es encuadrable en uno u otro título competencial" (vid. f.j. 2).

«Entrando en el examen de esos cuatro grupos y con respecto al primero de ellos (artículo 2.1, núm. 1.3 y artículo 4.4, núms. 1, 2, 3 y 5), la argumentación de la Junta de Galicia se efectúa, no tanto porque su contenido esté carente de título competencial, sino por no establecer una nítida separación entre los espacios -dentro de los puertos, aeropuertos y terminales aduaneras afectos al tráfico internacional- en los que deba desarrollarse la actuación administrativa de sanidad exterior y aquéllos otros en los que la Comunidad Autónoma puede y debe ejercer su competencia de desarrollo legislativo y ejecución en materia de sanidad interior (...)

Los preceptos impugnados, rectamente entendidos, en nada pueden obstar al ejercicio de las competencias de titularidad autonómica, pese a que puedan ejercerse sobre un espacio común. Todos ellos están dirigidos (artículo 1, 2.1 y 4, en el encabezamiento de este último precepto) exclusivamente a actividades desarrolladas en relación con las condiciones sanitarias del tráfico internacional, como claramente se desprende de una lectura sistemática de dichos preceptos ( ... ) Con este entendimiento sistemático, que en todo caso implica la delimitación de la competencia estatal con relación tan sólo a supuestos de tráfico internacional de mercancías o sujetos, y teniendo en cuenta la doctrina del Tribunal sobre la posibilidad de coexistencia en un mismo espacio físico del ejercicio de competencias distintas, puede afirmarse que este primer grupo de preceptos en nada infringe el orden competencial establecido por lo que debe rechazarse en este punto la tesis del representante de la Comunidad Autónoma de Galicia» (vid. f.j. 4).

«No requiere mucha atención el planteamiento del conflicto respecto del artículo 2.1, núm. 5 del Real Decreto impugnado. Prescribe este apartado que corresponden al Ministerio de Sanidad y Consumo, en materia de sanidad exterior y sin perjuicio de las competencias de otros 
organismos o departamentos ministeriales, "todas aquellas actividades concordantes que se determinen en el futuro", lo que el representante de la Junta de Galicia - para quien la concordancia a que se refiere el texto se subsume en la noción de concurrencia-, entiende como una invasión de las competencias concurrentes de la Comunidad Autónoma, en la medida en que se habilita exclusivamente al Estado para determinar el ámbito de esa misma concurrencia.

Pero, aparte de la difícil intelección de alguno de los términos empleados en el planteamiento del conflicto - pues no está claro qué quiera decirse con la frase "la concordancia se subsume en la concurrencia»-, lo menos que puede afirmarse del precepto ahora examinado es su absoluta inocuidad en orden a la delimitación de los respectivos ámbitos competenciales del Estado y la Comunidad Autónoma de Galicia. Es más, de la ubicación sistemática del mencionado precepto parece deducirse - además de su inequívoca referencia a actividades de control sanitario en supuestos de tráfico internacional- que su sentido no alcanza a la delimitación de competencias entre el Estado y las Comunidades Autónomas sino, a lo más, entre los distintos departamentos ministeriales y organismos de la administración estatal. De ahí que, insistiendo en la imposibilidad de que con tales términos se afecte al orden competencial establecido, tampoco en este extremo pueda imputarse ninguna tacha de exceso competencial al Estado" (f.j. 5).

«En lo que se refiere al artículo 7.1 -y por conexión con él del artículo 2.1, núm. 4 b) - del Real Decreto, aduce el representante de la Junta de Galicia que la competencia en materia de autorizaciones para el traslado internacional de cadáveres y restos cadavéricos a que allí se hace alusión lartículos 29 y 36 d) del Decreto 2.263/1974, de 20 de julio, por el que se aprueba el Reglamento de policía sanitaria mortuoria, R.P.S.M.] fue transferida a la Junta de Galicia por el artículo $33.1 \mathrm{c}$ ) del Real Decreto 1.634/1980, de 31 de julio, sobre transferencia de competencias en materia -entre otras- de sanidad a la Junta de Galicia, de modo que el Real Decreto impugnado vulnera en este punto el sistema de distribución de competencias hasta entonces vigente, que deriva en este caso, del Real Decreto de transferencia. Y no es ocioso recordar, por lo que ahora interesa, que este Real Decreto es anterior a la entrada en vigor del Estatuto de Autonomía de Galicia, siendo así que en el régimen preautonómico los Decretos de transferencia atribuían esa competencia, a diferencia de lo que ocurre con las transferencias postestatutarias, según las cuales tan sólo se traspasan los medios e instrumentos para el ejercicio de las mismas (SSTC 25/1983, 76/1983, 87/1983 y 88/1983, entre otras muchas posteriores). 
Por lo demás, también tiene claramente establecido este Tribunal que la finalidad instrumental propia de los Decretos de transferencia impide que de ellos se extraiga un resultado que se sobreponga a la interpretación que provenga de las cláusulas constitucionales y estatutarias y de las leyes llamadas por éstas para delimitar competencias, que como tales integran el bloque de la constitucionalidad (explícitamente, STC 278/1993, fundamento jurídico $4 .^{\circ}$; en sentido similar, SSTC $103 / 1989,147 / 1991$ y 220/1992). En concreto, no resulta posible deducir de un Decreto de transferencia, elaborado con anterioridad a la entrada en vigor del Estatuto, un título competencial no recogido por éste y que, por lo demás, pudiera colisionar con una explícita afirmación de competencia exclusiva estatal determinada por la Constitución (artículo 149.1.16).

De todo ello resulta que, en la medida en que del E.A.G. no se desprende ninguna competencia de la Comunidad Autónoma en lo relativo a sanidad exterior, por ser esta materia inequívocamente de competencia exclusiva estatal -incluso en lo que se refiere al ni de la pura ejecución, STC $252 / 1988$, fundamento jurídico $3 .^{\circ}-$, cualquier atribución anterior que pudiera resultar del Decreto de transferencia debe entenderse como no subsistente con posterioridad, de modo que en nada puede colisionar con la afirmada en el artículo 7.1 del Real Decreto impugnado, plenamente coherente, esta última, con el bloque de la constitucionalidad.

En puridad, en dicho precepto no se innova el orden de competencias que resulta de la Constitución y el Estatuto, conforme al cual es claro que incluso competencias de pura ejecución -como la relativa a las autorizaciones y comunicaciones previstas en el R.P.S.M.- en materia de traslado internacional de cadáveres y restos cadavéricos pertenece al Estádo, en la medida en que de él es indudable que pueden derivarse riesgos sanitarios por el mero hecho del tráfico internacional" (vid. f.j. 6).

"Queda por estudiar el último de los preceptos controvertidos, relativo a la competencia del Ministerio de Sanidad para la emisión de informes técnicos y custodia de los decomisos de sustancias estupefacientes y psicotrópicas de tráfico ilícito (artículo 12). Se halla planteado el conflicto, a este respecto entre la alegación del representante de la Junta de Galicia para quien las actividades aquí recogidas son de pura ejecución y deben encuadrarse en la cláusula general de competencia ejecutiva que el artículo 149.1.16 C.E. y 33.1 E.A.G. le reconocen en materia sanitaria, y la del Abogado del Estado, para quien las actividades de emisión de informes y custodia allí previstas recaen en el título com- 
petencial de sanidad exterior o, en todo caso, de relaciones internacionales (artículo 149.1.3 C.E.), lo que excluye cualquier competencia, incluso puramente ejecutiva de la Comunidad Autónoma.

No obstante un examen atento de la disposición impugnada llevá a la conclusión de que ninguno de los títulos competenciales alegados es adecuado para la resolución de la controversia. En efecto, tal y como ya dijo la STC 54/1990 (fundamento jurídico $4 .^{\circ}$ ), tanto los informes técnicos, como la custodia atribuidas por el artículo 12 a la competencia del Ministerio de Sanidad y Consumo, se refieren a «sustancias estupefacientes y psicotrópicas de tráfico ilícito", respecto de las cuales el artículo 338 L.E.Crim. determina su puesta a disposición de la autoridad judicial. Las actuaciones a que se refiere el artículo 12 de informe, control y custodia, se encuentran, por tanto, dada la calidad de las sustancias a que se refieren, bajo disposición de la propia autoridad judicial. Así «cualquier actuación administrativa se encuentra aquí conectada con dos materias sobre las que la competencia estatal exclusiva está fuera de cuestión: la de seguridad pública (artículo 149.1.29 C.E.), de una parte, y la de administración de justicia (artículo 149.1.5 C.E.), de la otra, pues sólo como colaboradores y auxiliares de Jueces y Tribunales actúan aquí los órganos de la Administración Civil del Estado, a quien corresponde por tanto, sin lugar a dudas la competencia para el ejercicio de las actuaciones réferidas" (STC 54/1990, fundamento jurídico $\left.4 .^{\circ}\right)$. Así las cosas, la competencia del Estado resulta inequívoca, por más que el mencionado precepto resulte irrelevante frente a las determinaciones que la autoridad judicial pueda acordar en cada caso» (f.j. 7).

Fallo: Declarar que la competencia controvertida corresponde al Estado.

(Sentencia n. ${ }^{\circ} 329 / 1994$, de 15 de diciembre. Pleno. BOE 13-1-1995. C. de la Vega Benayas). 